\title{
Integrated Supercritical Fluid Extraction and Bioprocessing
}

\author{
Owen Catchpole, Stephen Tallon, Peter Dyer, Fernando Montanes, \\ Teresa Moreno, Erika Vagi, Wayne Eltringham and Jagan Billakanti \\ Integrated Bioactive Technologies, Industrial Research Limited, Lower Hutt, New Zealand
}

Received 2012-10-23, Revised 2012-11-10; Accepted 2012-11-20

\begin{abstract}
Supercritical fluids are increasingly being used and promoted at a laboratory and pilot scale to produce high value, natural bioactives from biologically based raw materials. Supercritical $\mathrm{CO}_{2}$ is overwhelmingly the solvent of choice for these operations, but is largely limited to the processing of dry raw materials and the extraction of low polarity, low molecular weight compounds. The use of cosolvents and the use of alternative 'near-critical' extraction fluids such as dimethyl ether show potential to mitigate these limitations. Commercialisation of new supercritical extraction processes has arguably been limited because the supercritical extraction process has been developed in isolation of other processing steps necessary to achieve a successful product. This study reviews recent developments in integrated processing that incorporate the use of supercritical fluids for bioseparations and in particular process schemes that produce high value natural bioactives. Integrated processes include prior operation (fermentation, extraction, enzyme pre-treatment, physical fractionation or size reduction) followed by supercritical extraction or fractionation and processes in which operations are carried out in situ in supercritical fluids (supercritical chromatography, enzymatic conversion, precipitation and coating of solutes). The use of co-solvents and alternative extraction solvents in these processes is discussed. Prospects for future developments are also discussed.
\end{abstract}

Keywords: Supercritical Fluid, Extraction, Fractionation, Fermentation, Enzymatic Conversion, Integrated Processing

\section{INTRODUCTION}

Supercritical fluid extraction using $\mathrm{CO}_{2}$ is now an established industrial process for the production of high value natural products. Typical products include hop extracts, decaffeinated tea and coffee, herb and spice extracts, medicinal herb extracts and seed and marine oils (King and Bott, 1992; Martinez, 2008). More recent examples include extraction processes where an undesirable component is removed, such as cork taint from corks for the wine industry (Taylor et al., 2000) and pesticides from medicinal herbs such as ginseng (Quan et al., 2004). $\mathrm{CO}_{2}$ is the solvent of choice for all these processes. In general, $\mathrm{CO}_{2}$ is a relatively poor solvent, but is highly selective for non-polar lipophilic compounds. The solvent properties of $\mathrm{CO}_{2}$ towards classes of natural products have been described extensively elsewhere (Gupta and Shim, 2006). Solubility generally decreases for a class of compound with increasing molecular mass and at fixed molecular mass decreases with increasing polarity of a compound. To process compounds that are more polar, a wide range of polar co-solvents can be used, although for products that are used in dietary and cosmetic applications, the range of options is generally restricted to non-toxic foodacceptable solvents such as ethanol and propanol. It is possible to carry out extractions using other liquefied gases, such as propane and dimethyl ether (DME), under conditions close to their critical point. These gases, when liquefied, are good solvents for lipophilic compounds Lower Hutt, New Zealand 
with substantially greater solubility limits than $\mathrm{CO}_{2}$. In the case of DME it will extract polar lipids (Catchpole et al., 2008; 2009a; 2010) and to some extent water (Yano et al., 1978; Catchpole et al., 2007a; Pozo and Streett, 1984), making it a flexible solvent for many bioprocessing operations. Both propane and DME are suitable for food applications and are recognized as approved solvents for use in some countries including New Zealand and Australia. Use of liquefied gases, or near-critical fluids, has some similarities to use of supercritical fluid $\mathrm{CO}_{2}$, including low temperature operation, easy separation of solvent from product due to the large difference in volatility, high solvent recyclability and low solvent residues.

\subsection{The Need for Integrated Bioprocessing}

Despite the benefits and flexibility of supercritical and near-critical solvent systems in bioprocessing it is advantageous and in many cases necessary, to carry out additional processing operations either before or during supercritical fluid processing and to consider it as a whole integrated process. This approach allows the overall process to be tailored towards better overall fractionation, targeting of specific compounds or product properties and utilization of the supercritical fluid solvent state to enhance or create new processing opportunities that could not be realized in conventional solvent systems.

Integrated bioprocessing operations are divided into four categories here:

- Upstream fractionation. In this case biological materials are pre-processed by solvent extraction or physical separations to produce a partial concentration of desired product compounds, to remove compounds (for example carbohydrates) that may inhibit downstream processing, or simply to dry or mill material to a suitable form

- Production of tailored feedstocks by microorganisms. This is a rapidly growing field for renewable and high intensity production of a wide range of biochemicals for health, dietary, materials and also fuel applications. This new field has associated bioprocessing challenges, particularly with extraction and separation of compounds from dilute aqueous fermentation biomass

- Pre-processing by chemical or enzymatic reaction. Biological compounds of interest are often strongly bound to cellular structures and chemical or enzymatic treatment can be an effective way of facilitating extraction. Some compounds of interest can also be processed more effectively in a different form, for example omega-3 fatty acids must be separated from the glycerol backbone if they are to be processed individually and ester forms of fatty acids are generally easier to solubilise

- In situ processes. This includes adsorption or reaction operations that are carried out under supercritical (or near-critical) solvent conditions. The supercritical fluid solvent acts as a high mass and heat transfer solvent system with controllable solvent density ideal for many adsorption/desorption operations. In the case of enzymatic processing, continuous processing is possible and continuous removal of reaction products gives potential for more complete reaction to occur

A description and examples of these types of integrated operation is given in this study.

\subsection{Supercritical Fluid Systems for Integrated Bioprocessing}

Figure 1 shows typical flow diagrams that could be applied to an integrated process. Pre-processed feed materials are either liquid solutions, fluids with suspended solids, or dry materials. Three supercritical fluid contacting arrangements are shown.

Arrangement (i) is commonly used in the extraction of solid feed materials. A pressure vessel is loaded with a basket or canister that contains the solid feed material but allows the passage of liquid or supercritical solvent to pass through the bed of solids until the bed is depleted of soluble material. The loaded solvent phase passes optionally to a further processing step, or is depressurized through one or more stages to separate the solvent from extracted material. Solvent flow can be either up flow or down flow through the bed. Cosolvents can be premixed with the solvent stream as required. Multiple vessels can be operated in sequence to achieve semi-continuous batch processing, or with some modification a fully continuous solids transfer system may be suitable for some low pressure applications (Waibel et al., 2008).

Arrangement (ii) is used for processing liquid or slurry feed solutions. The contacting can be carried out as either a stirred tank or a counter current column with or without internal packing. The feed solution is typically dissolved in a solvent that has partial or complete miscibility in the supercritical fluid. When the feed solvent has limited solubility and is fed at a sufficiently high ratio to the supercritical fluid flow, then two liquid phases will develop and a continuous recovery of a liquid raffinate phase may be possible. If under- 
saturated conditions are used the solvent phase will mix completely with the supercritical fluid, causing solutes that are not soluble in the supercritical fluid to precipitate. In either case, the supercritical fluid is typically a non-solvent for at least one solute in the feed solution and the process is referred to as an 'antisolvent' process. It is a very versatile processing operation. The solvent and supercritical fluid phases can be selected to give high solubility in the feed stream and rapid contacting in the supercritical fluid gives a high process throughput. Very high supersaturation can be achieved in operations involving nucleation and precipitation of solid solutes, known as the Supercritical Antisolvent (SAS) process. Simultaneous fractionation of compounds can also be achieved if some solutes are soluble in the supercritical fluid + solvent phase that is formed (Catchpole et al., 2009b).

Arrangement (iii) is used for loading a feed solution onto a packed bed using a supercritical fluid as a carrier phase or as an eluting phase. This can be used for contacting a solute laden solvent phase with a solid packing for adsorption or chromatography, or the solid phase could be an enzymatic, ion exchange, or catalyst bed. Multiple vessels can be used for batch processes like adsorption/desorption to achieve semicontinuous operation.

These contacting arrangements can potentially be used in sequence. The feed stream to an adsorption bed, for example, could itself be a supercritical fluid solution from a previous packed bed extraction step.

The right hand side of Fig. 1 shows a three stage separation process. Because a supercritical fluid has a continuously variable density with pressure it is possible to reduce the pressure (and density) in stages and fractionate some compounds from a mixture. Larger molecules and slightly polar compounds that are poorly soluble in $\mathrm{CO}_{2}$, will separate at high pressures. At medium pressures shorter chain molecules can be recovered and finally co-solvents and volatiles like plant essential oils can be recovered at the lowest pressure. After the third stage the supercritical fluid solvent is in a gas state and is usually condensed and directly recycled. Extracts recovered from the separators will contain some dissolved supercritical fluid which could be recovered in a secondary depressurization step, or simply flashed to atmosphere. Co-solvents recovered from the separator may be able to be directly recycled to the process in some applications.

\section{UPSTREAM FRACTIONATION OF BIOMASS}

The efficacy of supercritical extraction for recovery of valuable compounds from large volume and/or feed material with low concentrations can be greatly improved by combination with an effective upstream fractionation process. This can include very simple operations such as removing husks, shells, or skins, that do not contain the desired solutes and straining, pressing, or centrifuging high water content materials to give an aqueous phase and a residual solid biomass which may be concentrated in oils and low polarity compounds. Drying is also important to many extraction processes. The type of drying method used can affect the stability and quality of the product. Higher temperature operations such as vacuum evaporation or spray drying are suitable in some cases. Freeze drying is an alternative to higher temperature evaporation for compounds that are thermally labile but it is an expensive process to carry out and some protein based substrates, or live microorganisms, may still be damaged.

More complex upstream fractionation, followed by supercritical processing, can include any combination of chemical and physical processing operations. Five process technologies are described below: physical processing (drying, pressing and centrifuging) of wet feed materials; solvent extraction of biomass followed by supercritical antisolvent fractionation of the solution to yield a broad range of compounds; supercritical antisolvent production of salts and proteins from aqueous solutions, use of a solvent-based urea fractionation to concentrate Polyunsaturated Fatty Acids (PUFA) followed by supercritical antisolvent fractionation to recover the PUFA and physical processing of dairy streams to concentrate desired lipids, followed by supercritical extraction or fractionation to recover the lipids.

\subsection{Drying, Pressing and Centrifuging}

$\mathrm{CO}_{2}$ is a hydrophobic solvent, which, with a few notable exceptions such as the decaffeination of green coffee beans (Lack and Seidlitz, 1992), cannot be used to extract wet biomass. Therefore most raw materials need to be dried and then ground before they can be extracted. While both operations are simple, they are critical in obtaining a high yield of extract and to minimization of degradation. Surprisingly little effort is put into optimizing either or both of these operations at an industrial scale. Drying technologies can be categorized as thermal (use of hot air and/or heated surfaces at atmospheric pressure, e.g., spray drying, oven drying, refractance window), vacuum (e.g., freeze-drying) and chemical (use of a dehydrating solvent, including use of $\mathrm{CO}_{2}$ or DME). 

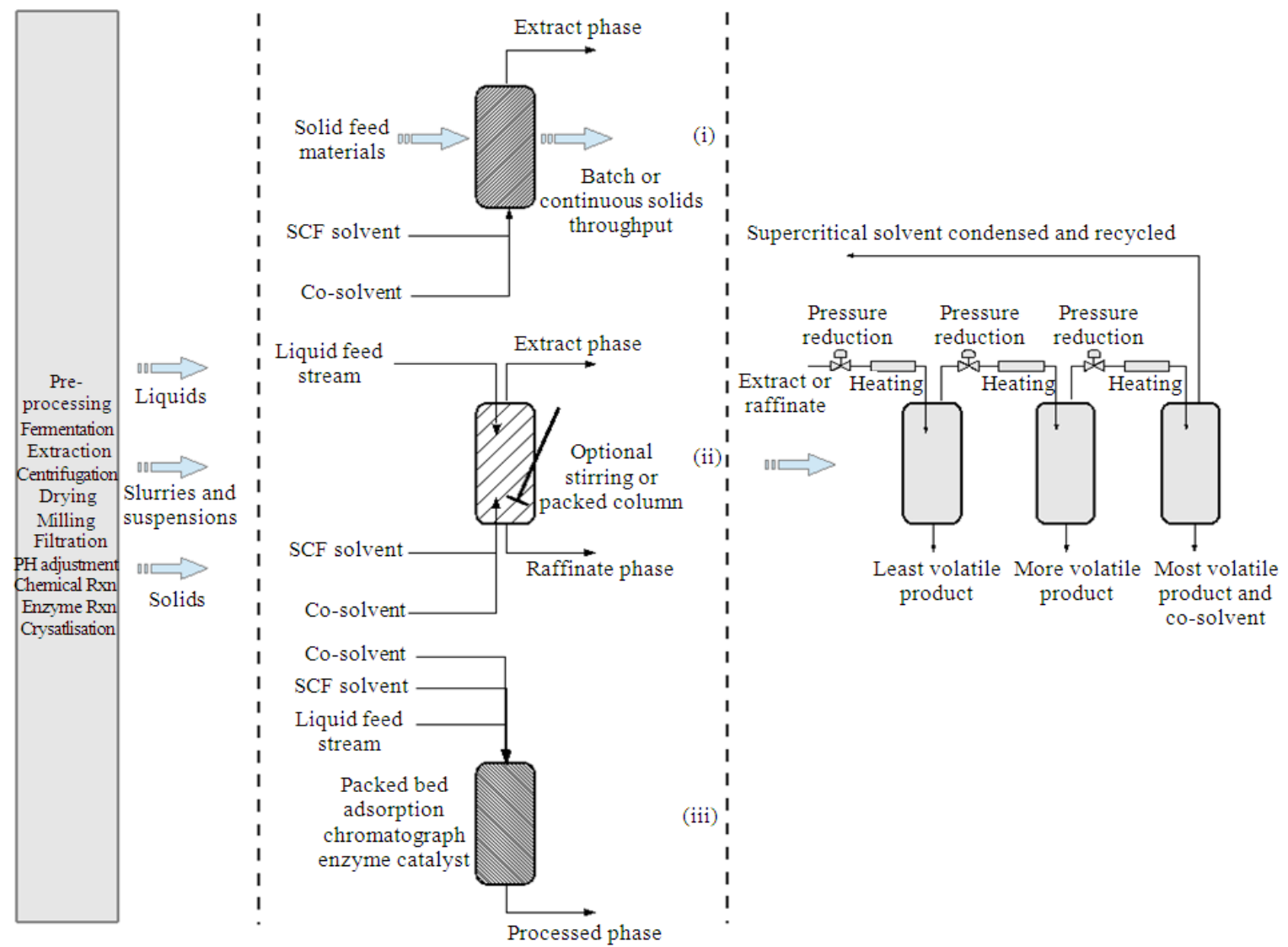

Fig. 1. Supercritical fluid processing scenarios that can be integrated with other bioprocessing operations

Freeze-drying is the most energy and capital intensive means of drying, but results in the lowest degradation of compounds that are sensitive to heat, light and/or oxygen. It is therefore the method of choice for drying materials that have high levels of polyunsaturated lipids or lipophilic antioxidants. The freeze-dried material must be packaged as quickly as possible after production, as the porous nature of the dried product allows very good access to oxygen. The dried material is usually very low density and must be ground before extraction.

Spray drying is the most commonly practiced drying technology and is used at a very large scale to produce powdered dairy products. The particles produced are in general not porous and the amorphous outside shell of the particle can be a strong barrier to mass transfer, although in many cases the powder produced can be extracted without further processing. Many plant materials are air dried, or are naturally low in water content, such as seeds.
The extraction of compounds from wet biomass using $\mathrm{CO}_{2}$ is possible when the solutes are highly soluble in $\mathrm{CO}_{2}$ (e.g., flavours and fragrances) and the water content has been reduced to the point where it does not provide a barrier to mass transfer. The acidic nature of $\mathrm{CO}_{2}$ when dissolved in water needs to be taken into account if acid-labile materials are to be extracted. The dissolution of $\mathrm{CO}_{2}$ into the aqueous phase of plant materials with a very high water content can also cause the material to become mucilaginous and for the material to 'cook' when heated in $\mathrm{CO}_{2}$ above room temperature.

We have overcome some of these issues by developing a "squeeze and extract" process which has been applied to a number of herbs and vegetables to make them amenable to $\mathrm{CO}_{2}$ extraction. The plant material is firstly coarsely ground using a mincer or knife mill and is then passed through a dejuicing screw press or alternatively is centrifuged. The juice phase normally has little to no $\mathrm{CO}_{2}$ extractable material. The residual partially dewatered plant material is then 
extracted with $\mathrm{CO}_{2}$. This process has been applied to the extraction of oleoresin from celery and oregano (Catchpole et al., 2004a); sulphur-rich compounds from onions; oleoresin and essential oil from sage and gingerols and essential oil from ginger root.

\subsection{Supercritical Antisolvent Fractionation Technology (SAFT)}

SAFT is an extremely versatile process. In general terms, an upstream process takes place using an organic solvent system consisting of a water-miscible organic solvent and water and the solution resulting from this operation is then processed using a super-, or nearcritical solvent. The water content can range from zero to $\sim 100 \%$ and is optimized according to the range of compounds to be extracted and the supercritical fluid used to fractionate the mixture thus obtained. Examples demonstrating the breadth of the possibilities that we have investigated are shown in Table 1. They include solvent extraction of a plant or animal material followed by SAFT (Catchpole et al., 2009b; 2006); urea fractionation of fatty acids (or derivatives thereof) followed by polyunsaturated fatty acid (PUFA) recovery (Eltringham and Catchpole, 2008; Catchpole et al., 2002) fractionation of propolis tincture (Catchpole et al., 2004b), fractionation of phospholipids (Catchpole and Tallon, 2006) processing of aqueous streams containing protein and lipid (Catchpole et al., 2007a; Fletcher et al., 2003) and processing of algae in water or ethanol/water with DME extraction of lipids.

The principles of operationaresimple (Catchpole et al., 2009b). The organic solvent system is chosen such that it is capable of dissolving a broad spectrum of componentsand for practical purposes often consists of ethanol/water mixtures. The solvent mixture itself is usually only partially miscible with the near-critical fluid. The portion of the solvent that does dissolve in the near-critical fluid acts as a co-solvent, increasing the solvent power of the near-critical fluid. The most polar compounds that were previously dissolved in the organic solvent phase are precipitated from solution, along with at least part of the water present in the solvent phase. If supercritical $\mathrm{CO}_{2}$ is used as the near-critical fluid, the solutes dissolved in the near-critical phase can then potentially be separated into two or more extracts. Further modifications to the general process include a water-wash step, which can be used to wash medium polarity solutes out of the near-critical phase for $\mathrm{CO}_{2}$ based processes and a temperature change step to remove water from DME as the solubility of water in DME decreases with decreasing temperature (Pozo and Streett, 1984).

\subsubsection{Hydroalcoholic Extraction of Plant Antioxidants: Recovery of Diterpenes from Sage and Rosemary}

The extraction and recovery of diterpene antioxidants (carnosic acid, carnosol and methyl carnosate) is an exemplar process using this technology. The initial extraction of rosemary or sage leaf is carried out with an ethanol/water mixture. Optimal conditions for carrying out this extraction using a stirred tank have been reported elsewhere (Durling et al., 2007a). Briefly, the solvent is 70:30 mass ratio of ethanol to water and a solvent to dry ground leaf feed ratio of $4: 1$ is used. Extraction is carried out at $40^{\circ} \mathrm{C}$.

Table 1. Examples of supercritical antisolvent fractionation applications and the fractions produced

\begin{tabular}{|c|c|c|c|c|c|c|}
\hline $\begin{array}{l}\text { Upstream } \\
\text { process }\end{array}$ & Feed & $\begin{array}{l}\text { Near-critical } \\
\text { fluid }\end{array}$ & Raffinate & Extract 1 & Extract 2 & $\operatorname{Ref}^{b}$ \\
\hline Urea fractionation & Hydrolysed fish oils & $\mathrm{CO}_{2}$ & urea, water & $\begin{array}{l}\text { PUFA ethyl esters } \\
\text { or free fatty acids }\end{array}$ & $\begin{array}{l}\text { oxdn. products, } \\
\text { ethanol }\end{array}$ & $\mathrm{SA} 3,4$ \\
\hline Solvent extn. & Rosemary, sage & $\mathrm{CO}_{2}$ & phenolics & antioxidants & essential oil & SA1,2 \\
\hline Solvent extn. & Olive leaf & $\mathrm{CO}_{2}$ & flavonoids & oleuropein & vitamin E & SA1,2 \\
\hline Solvent extn. & Propolis & $\mathrm{CO}_{2}$ & phenolic oligomers & $\begin{array}{l}\text { aglycone } \\
\text { flavonoids }\end{array}$ & cinnamic acids & SA5 \\
\hline Solvent extn. & Phospholipids & $\mathrm{CO}_{2}$ & $\begin{array}{l}\text { phosphatidylserine, } \\
\text { phosphatidylinisitol }\end{array}$ & $\begin{array}{l}\text { phosphatidylcholine, } \\
\text { sphingomyelin }\end{array}$ & neutral lipids ${ }^{\mathrm{a}}$ & SA8 \\
\hline Solvent extn. & Berries & DME & sugars, acids & anthocyanins & & SA4 \\
\hline Dairy process & Serum, whey & DME & proteins, lactose & lipids & water $^{\mathrm{a}}$ & SA6,7 \\
\hline Reconstitution & Egg yolk powder & DME & proteins & lipids & water $^{\mathrm{a}}$ & SA6 \\
\hline Slurry with solvent & Algae & DME & alginates & lipids & water $^{\mathrm{a}}$ & \\
\hline
\end{tabular}

a; Co-extracted with Extract 1

b; See text for reference details 

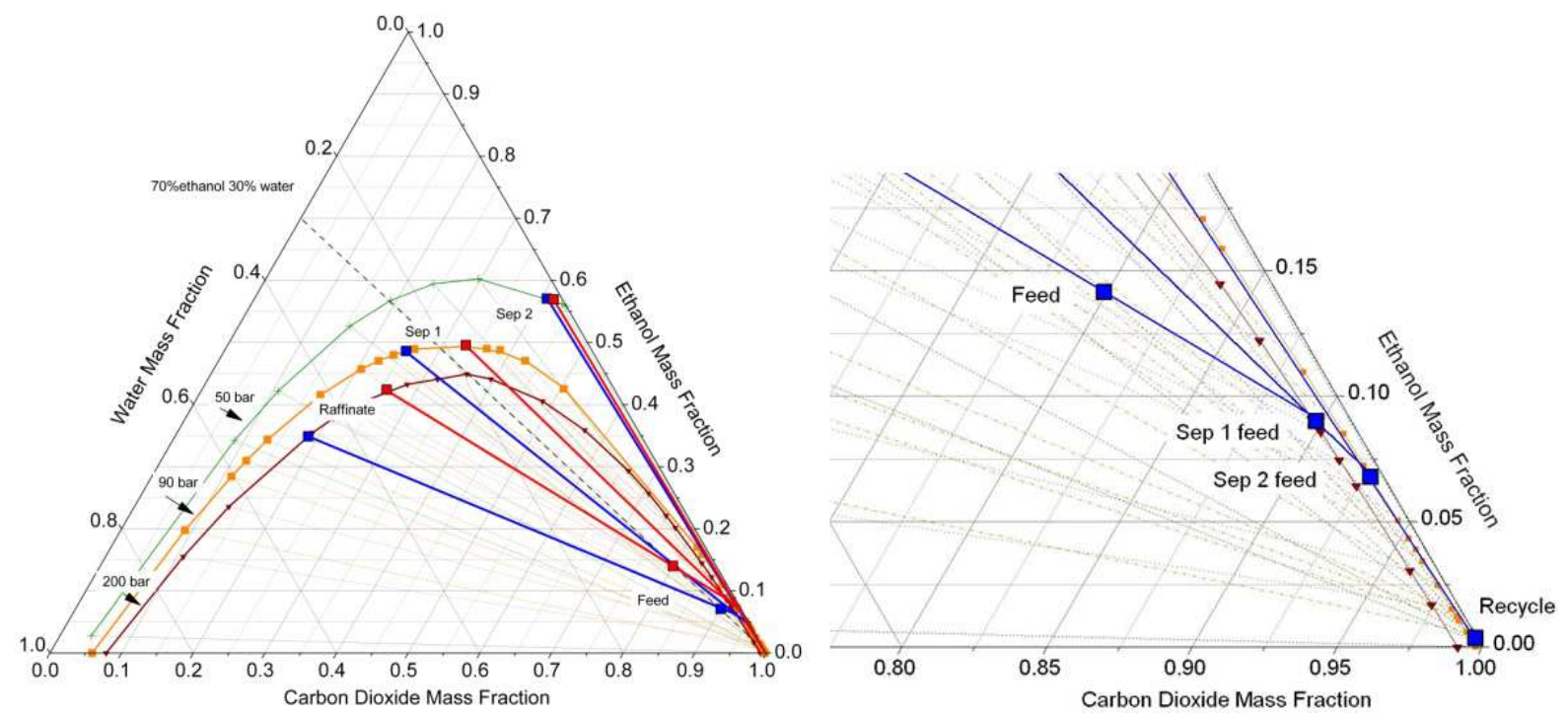

Fig. 2. Phase equilibrium compositions for antisolvent, first and second separator conditions at 10 and $20 \%$ feed solution to $\mathrm{CO}_{2}$ mass ratios

The solution obtained is filtered and then processed using SAFT. Previous phase equilibrium measurements for $\mathrm{CO}_{2}$ /ethanol/water (Durling et al., 2007b), coupled with experiments at a pilot scale, were used to establish suitable conditions for the supercritical antisolvent stage and also for the 2 or 3 stages of separation. Figure 2 shows the predicted phase equilibrium for $\mathrm{CO}_{2} /$ ethanol/water at 200 bar for the antisolvent step at feed rates of 10 (blue) and $20 \%$ (red) by mass feed to $\mathrm{CO}_{2}$ mass ratio. At the lower feed rate, the raffinate has a higher amount of water and thus lower loss of ethanol and similarly the first extract also has a higher amount of water which is co-extracted by the $\mathrm{CO}_{2}+$ ethanol. Interestingly, this water content of the extract phase results in some extraction of the polar antioxidant, rosmarinic acid. As the feed solution to supercritical fluid ratio is increased, the loss of ethanol into the raffinate increases and the efficiency of separation of rosmarinic acid from diterpenes begins to decrease. However, the process economics improve because of the more rapid throughput of feed solution.

The recovery of Rosmarinic Acid (RA), diterpene antioxidant compounds carnosic acid, carnosol and methyl carnosate (CT) and essential oil/oleoresin (EO) is shown as a function of feed to $\mathrm{CO}_{2}$ flow rate ratio in Fig. 3 for the raffinate, first and second separators and the concentration of these same compounds in the same product streams is shown in Fig. 4. Also shown in Fig. 4 is the concentration of these compounds in the feed solution. It is possible to generate second separator products containing greater than $30 \%$ by mass diterpenes. In recent work, 3 stages of separation were applied, which enabled very good separation to be achieved between triterpenes (oleanolic acid + ursolic acid) and chlorophyll (first separator); diterpenes (second separator) and essential oil and oleoresin compounds (third separator). The diterpene concentration in the second separator can exceed $50 \%$ by mass.

\subsubsection{Supercritical Antisolvent Precipitation of Solutes}

The supercritical antisolvent process can also be used to generate particulate materials and reviews of the process and applications are given by Shoyele and Cawthorne (2008); Jung and Perrut (2001); Jessop and Subramaniam (2007); Tallon and Catchpole (2008) and Fages et al. (2004) among others. Because of the flexible density of the antisolvent phase, a range of particle morphologies can be produced as well as encapsulated particles or solid dispersions. The low fluid viscosity and high rates of mass transfer that can be achieved enable high levels of supersaturation and rapid nucleation of very fine particles. Control over the physical form of particles is useful in many applications where the physical form of the product affects its active properties. The particle size, for example, can affect the rate of solubilization and also bioavailability of some pharmaceuticals and nutritional foods. 


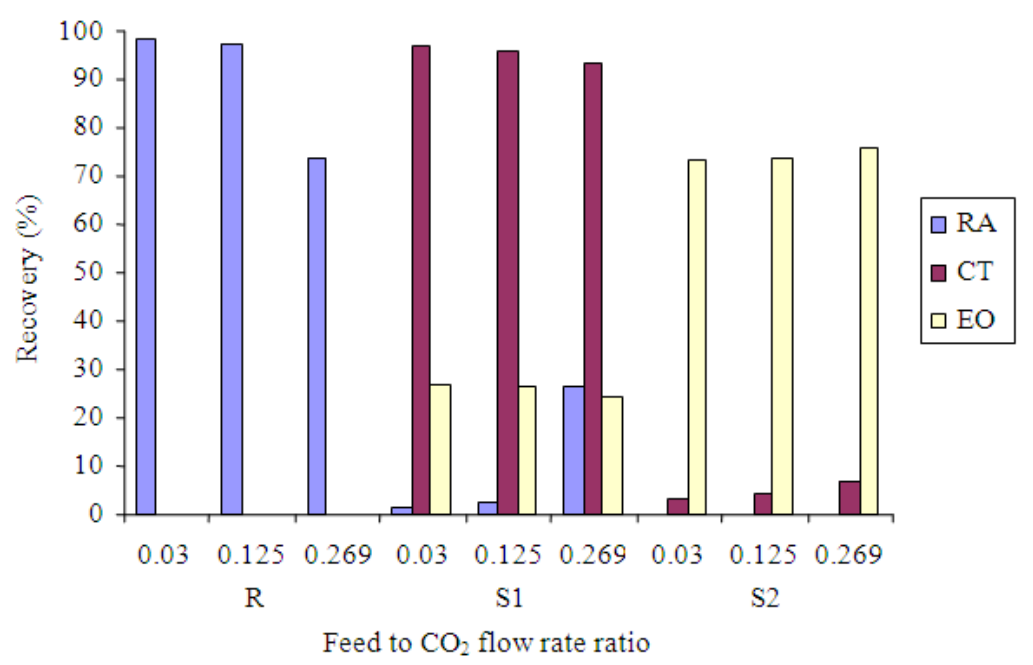

Fig. 3. Recovery of key sage extract components in raffinate $(\mathrm{R})$, first separator $(\mathrm{S} 1)$ and second separator $(\mathrm{S} 2)$ products. $\mathrm{RA}=$ rosmarinic acid; $\mathrm{CT}=$ carnosic acid type (diterpene) compounds, $\mathrm{EO}=$ essential oil and oleoresin

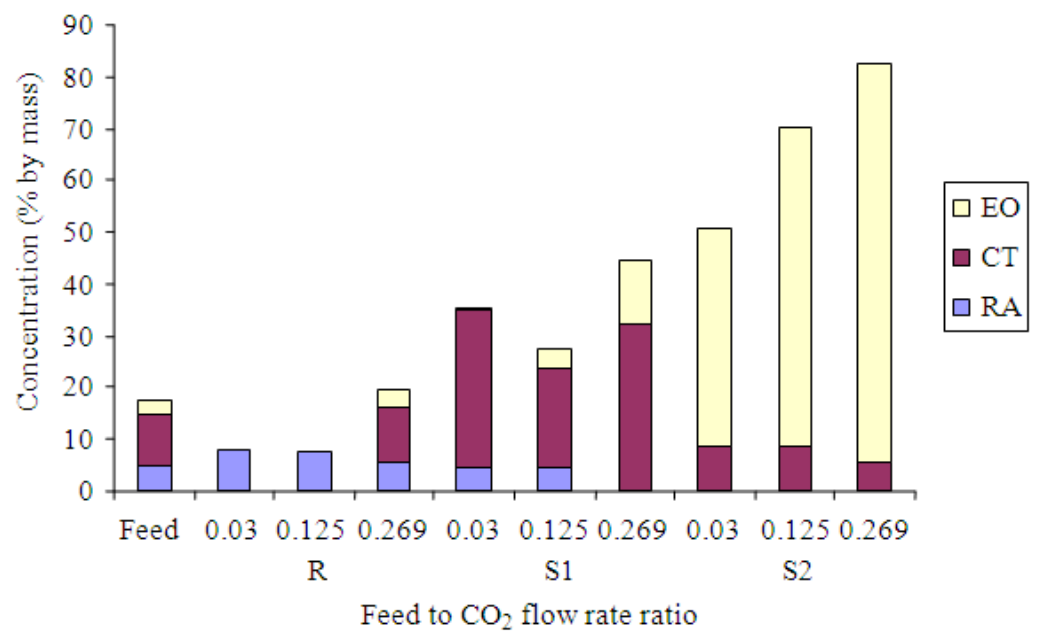

Fig. 4. Concentration of key sage extract components in raffinate $(\mathrm{R})$, first separator $(\mathrm{S} 1)$ and second separator $(\mathrm{S} 2)$ products. $\mathrm{RA}=$ rosmarinic acid; $\mathrm{CT}=$ carnosic acid type (diterpene) compounds, $\mathrm{EO}=$ essential oil and oleoresin

Physical form also affects stability, handling, aerodynamics of inhalable products and even perceptions of taste and texture. Supercritical antisolvent processing can generally be carried out at low temperature, which is important for many thermally labile compounds to prevent degradation or conformational changes. The low processing temperature of supercritical fluid systems and the low solvent residues that can be obtained give an advantage in some cases over alternative approaches such as milling, drying and liquid solvent or temperature change induced crystallization.
There are two main classifications of supercritical antisolvent precipitation process depending on which phase is continuous and which is dispersed. When the supercritical fluid phase is continuous and the solvent feed stream is dispersed into it, the process is commonly known as Supercritical Antisolvent (SAS). The solvent phase needs to be at least partially miscible with the antisolvent and the process is generally operated so that solvent is completely and rapidly removed into the antisolvent phase leaving a mostly solvent free precipitated product. Under conditions where the mixture 
of the solvent and antisolvent are still in a supercritical fluid region, particles will form without interference from surface tension associated with liquid-gas boundaries. Examples of compounds processed include insulin, hydrocortisone, lysozyme, albumin, (Shoyele and Cawthorne, 2008). Plant and dairy products (Catchpole et al., 2007a; Tallon et al., 2005) have also been processed. Figure 5 shows an example of particles of potassium bicarbonate formed by this process, by precipitation (and simultaneous reaction) of potassium hydroxide with carbon dioxide from a solution in ethanol.

When the supercritical antisolvent forms the dispersed phase the process is often called Gas Antisolvent (GAS). The solution forms the continuous phase and the supercritical antisolvent is introduced, gradually decreasing the solvent capacity of the solution until particles precipitate. Further washing with the supercritical fluid can remove the majority of the solvent from the system. This has been used for many systems, including proteins, but is a batch process with more limited control over the particle size.

The antisolvent particle formation process has some flexibility in choice of the upstream solvent used to dissolve the solute, although this choice may be limited for applications that require non-toxic solvents. Suitable solvents for use with $\mathrm{CO}_{2}$ include alcohols, but solvents such as dichloromethane and dimethylsulfoxide (DMSO), have also been used. Coating and excipient compounds that are poorly soluble in $\mathrm{CO}_{2}$ can be processed using the right solvent, including a range of polymers, cyclodextrins, lactose and chitosan, as well as inorganics such as magnetite (Chattopadhyay and Gupta, 2002) for use in magnetic field directed drug delivery. Compounds including insulin and DNA have been successfully encapsulated and stabilized using these methods (Tandya et al., 2007). $\mathrm{CO}_{2}$ antisolvent systems are often used with DMSO or methylene chloride as the solvent and residues of these solvents in some products may be undesirable.

Use of other supercritical, or near-critical, fluids is possible, including ethane and ammonia (Shoyele and Cawthorne, 2008). Dimethyl ether has also been used to precipitate compounds directly from aqueous solution (Tallon et al., 2005). An example from our work is the precipitation of bovine serum albumin from solution in water by dispersing the solution into a countercurrent flow of liquid dimethyl ether. Resulting particles are shown in Fig. 6 for processing at 40 bar and $40^{\circ} \mathrm{C}$. Coprecipitation of proteins with a secondary matrix is also possible. Figure 7 shows composite particles produced by co-precipitation of a lipase (Amano) with $\beta$ - cyclodextrin from solution in water. Greater than $90 \%$ of the enzymatic activity was retained during processing.

Variations of these particle formation processes can be employed to form more complex systems, including the use of emulsions and sonication to aid phase dispersion. Surfactants and stabilizers can be added to limit re-agglomeration or deterioration of particles that are formed. Considerable research has also been carried out using supercritical fluids for particle coating applications. In organic systems this is largely driven by applications in drug delivery, where the aim is to develop a stable highly bio-available product with a controlled release rate, or to incorporate the drug within compounds that enable targeted delivery (Ginty et al., 2005). Applications in food, cosmetics and agricultural products also exist (Taki et al., 2001).

A wide range of other particle formation, encapsulation and impregnation applications exist using supercritical fluids as a solvent rather than an antisolvent. The supercritical solution is typically depressurized to remove the solvent and precipitate the solute. These processes are largely independent of upstream and downstream processing steps and are not discussed further here.

\subsubsection{PUFA Concentration by Urea Complexing and Supercritical Antisolvent Fractionation}

The recovery of Polyunsaturated Fatty Acids (PUFA) or esters from an upstream urea fractionation process using supercritical antisolvent fractionation technology is another exemplar process. Urea fractionation has been known since the 1950s as a way to separate unsaturated alkyl chains from saturated chains. Urea dissolved in solution can form a solid clathrate around hydrocarbon chains (around 4:1 urea:compound mass ratio) which is then insoluble in the solvent. The equilibrium constant for the formation of the clathrate depends on the temperature, degree of unsaturation, position of sites of unsaturation, hydrocarbon chain length and ratio of urea to hydrocarbon-containing molecules (Eltringham and Catchpole, 2008). The stability, or tendency to form clathrates increases with increasing saturation and chain length and decreasing temperature. The selectivity of the process is highly dependent on the ratio of urea to feed material and the temperature. The molecules containing the hydrocarbon moieties can at most be mono-substituted by non-alkyl groups-fatty acids and fatty acid esters can form complexes but triglycerides and phospholipids cannot for example. 


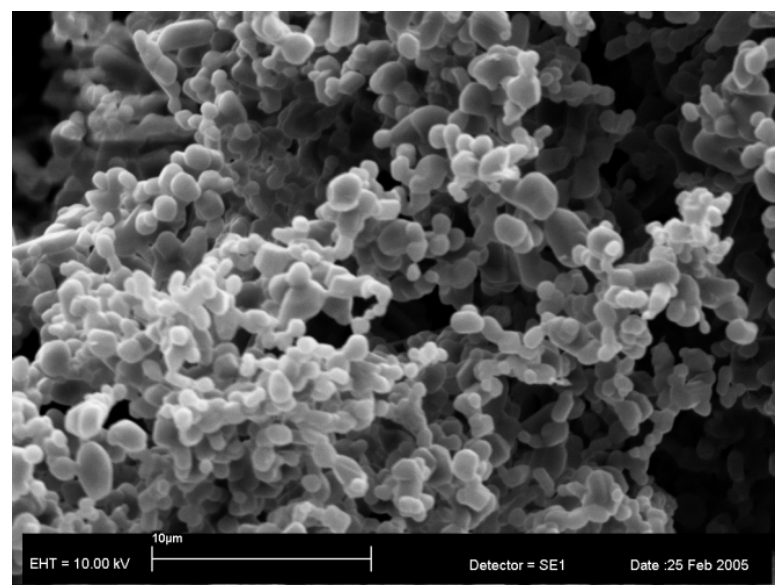

Fig. 5. Potassium bicarbonate formed by SAS precipitation of potassium hydroxide from solution in ethanol into supercritical $\mathrm{CO}_{2}$

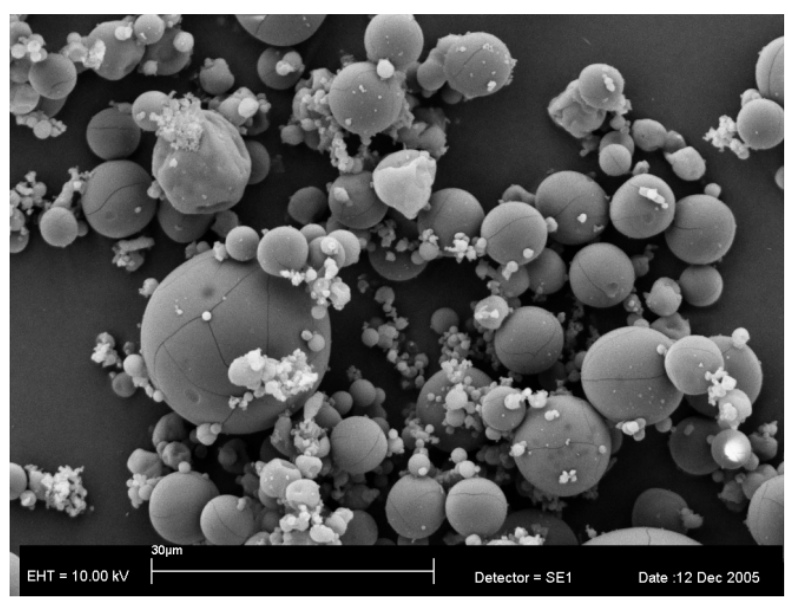

Fig. 6. Bovine serum albumin particles from aqueous solution using dimethylether as antisolvent

The most practiced form of the technology is to use urea dissolved in ethanol at high temperature and a mixture of ethyl esters as the feed material to form a miscible solution which is slowly cooled to induce clathrate formation. Unsaturated fatty acid esters stay in solution and are recovered by hexane extraction and water partitioning from the solution and the clathrates containing saturated and mono-unsaturated fatty acid esters are removed by filtration. This is a suboptimal process as the urea has limited solubility in the ethanol (approximately $10 \%$ by mass at $80^{\circ} \mathrm{C}$ ), which then entails high use of ethanol and low throughput of lipid, the urea clathrate is difficult to re-use and the ethanol and hexane are expensive to recover by distillation.

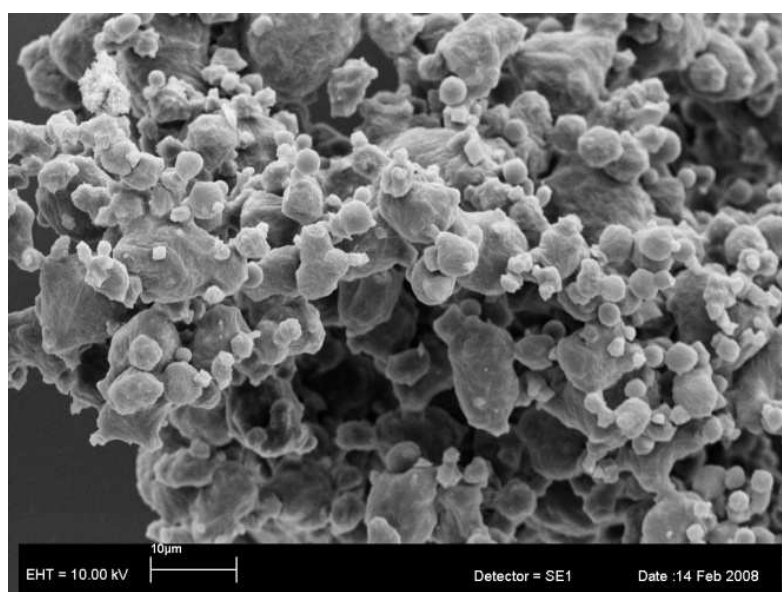

Fig. 7. Composite $\beta$-cyclodextrin and Amano Lipase precipitated from aqueous solution using dimethylether as antisolvent.

The process can be improved by adding water to the solution to increase the urea solubility, exchanging fatty acids for ethyl esters, which are more soluble in ethanol/water mixtures and exchanging the hexane/water partitioning process for supercritical antisolvent fractionation (Catchpole et al., 2002).

The supercritical antisolvent process can be applied to recovery of fatty acids from the clathrate phase, after it has been reheated in solvent to break up the complex and release the fatty acids. It can also be applied to the recovery of fatty acids from base-catalysed ethanol/water hydrolysate solutions of fish or plant oils. Here, the base salt is converted to potassium bicarbonate and the fatty acid ion is converted directly to free fatty acid through the decrease in $\mathrm{pH}$ engendered by $\mathrm{CO}_{2}$ dissolving in the aqueous ethanol phase. Salts, water and glycerol are precipitated in the raffinate and the fatty acids are recovered in the first separator.

A schematic of the urea separation process is shown below in Fig. 8. The solvent phase is filtered to remove the clathrate and is then compressed to the operating pressure before being contacted with $\mathrm{CO}_{2}$ using a static mixer placed inside the antisolvent fractionation vessel. Typically, the antisolvent vessel is operated at 200-300 bar and 313-333 K. Urea and water in the feed solution are precipitated into the antisolvent vessel and can be recovered from a valve at the bottom of the vessel. Polymerised fatty acids and long-chain oxidation products are also collected in this fraction if low grade oils are used as the feed material. If the solution is ethanol only, urea is precipitated inside the vessel as a solid. 


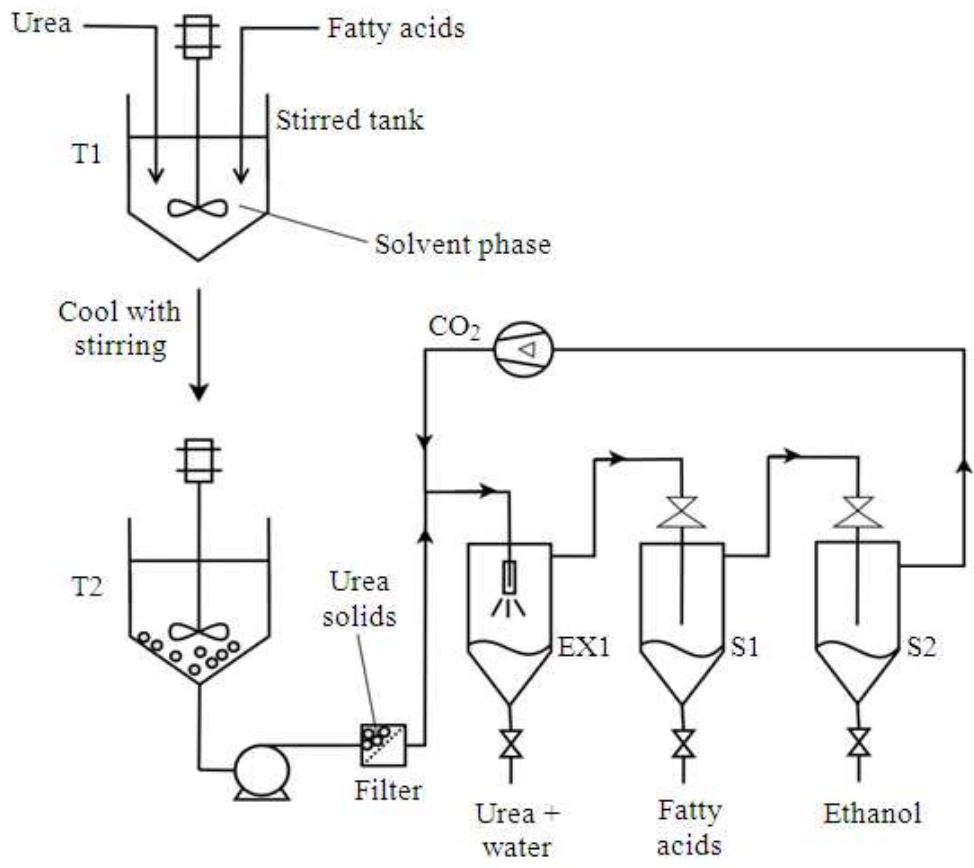

Fig. 8. Process schematic for the urea fractionation of fatty acids followed by supercritical antisolvent fractionation. T1 is the initial high temperature, T2 is the final temperature of the urea fractionation, EX1 is the antisolvent spray chamber, S1 is the first separator, $\mathrm{S} 2$ is the second separator

Optionally, a water-wash stream may be added, to improve the recovery of urea. The $\mathrm{CO}_{2}$ dissolves the majority of the ethanol present along with the desired polyunsaturated fatty acids. A small amount of urea is co-extracted in this phase and so preferentially, a water wash stream is added to the $\mathrm{CO}_{2}$ just prior to the pressure reduction valve of the first separator. The urea coextraction prompted us to determine the solubility of urea in $\mathrm{CO}_{2}+$ ethanol co-solvent (Catchpole et al., 2005). Surprisingly, the solubility of urea in $\mathrm{CO}_{2}+$ ethanol is almost independent of pressure within the range studied, but highly dependent on the co-solvent concentration. The water phase containing all the coextracted urea (and some ethanol) separates out from the free fatty acids inside the separator and can be collected using the valve at the bottom of the separator separately from the free fatty acids. The remainder of the ethanol and short chain odour compounds and oxidation products are recovered in the second separator product.

The filter cake containing the clathrate of urea and PUFA can also be reprocessed using the supercritical antisolvent fractionation process. Solvent is added to the cake and the mixture is heated and stirred until completely dissolved in solution and the fatty acids are liberated. The hot solution is then processed using SAFT under the same conditions. Again, the urea and water are precipitated and collected from the antisolvent let down vessel valve, the fatty acids are collected in the first separator and a minor fraction is collected in the second separator. The process has been tested on a wide variety of seed and fish oils (Catchpole et al., 2002) in which the aim has been to concentrate $\gamma$-linolenic acid, or EPA and DHA, respectively. Figure 9 shows the concentration of total PUFA, EPA and DHA from low grade Hoki oil which initially has 5\% EPA and 9\% DHA. After two cycles of the process, EPA has been increased to $20 \%$, DHA to $40 \%$ and total PUFA to $>90 \%$.

\subsection{Concentration and Extraction of Phospholipids from Dairy Streams}

Milk is a complex mixture of mainly proteins, lactose and lipids dispersed in water. The lipids are predominantly neutral lipids, with less than $0.1 \%$ by mass phospholipids. However, the phospholipids that are present are high in sphingomyelin and phosphatidylcholine, which are of interest in a variety of health and wellness applications. The complex lipid fraction in milk is also a rich source of gangliosides, lactosyl- and glucosyl-ceramide. 


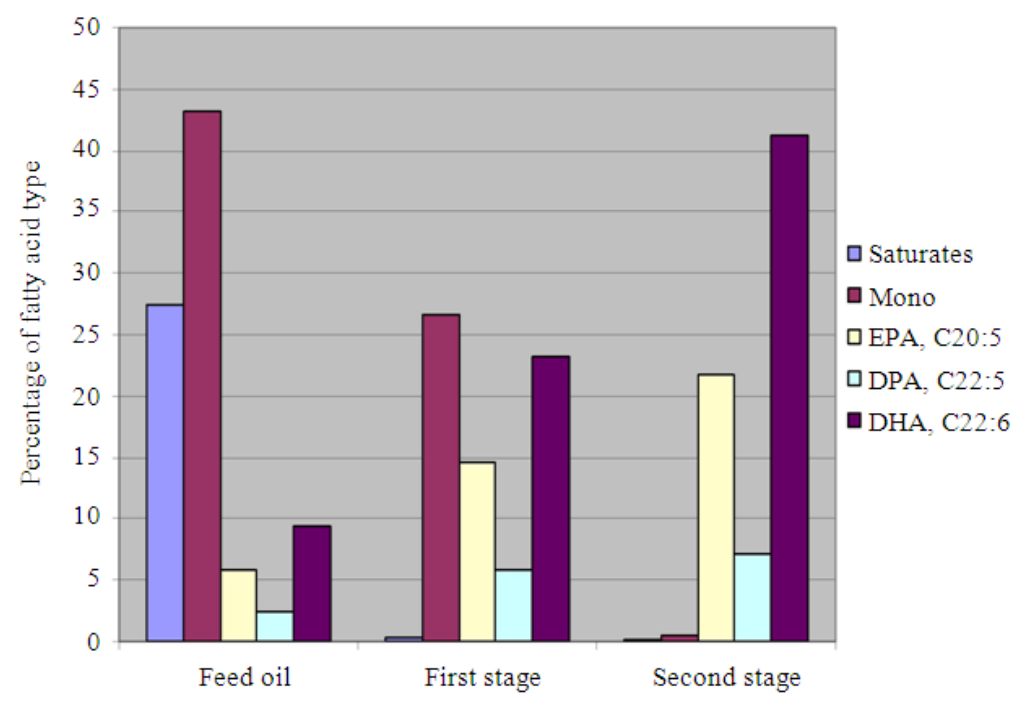

Fig. 9. Concentration of saturated and mono-unsaturated fatty acids, eicosapentaenoic acid (EPA), docosapentaenoic acid (DPA) and docosahexaenoic acid (DHA) in feed oil, first stage SAFT product and second stage SAFT product

There are two dairy streams that are produced in which the phospholipids have been substantially concentratedthese are beta serum, which is produced as a side stream from the production of anhydrous milk fat and skim milk (Catchpole et al., 2008; Fonterra, 2012) andHigh Fat Whey Protein Concentrate (HFWPC), which is produced from cheese making and casein precipitation operations. Current production methods for Whey Protein Isolates (WPI) from HFWPC, which typically contain at least $90 \%$ protein and less than $1 \%$ lipid on a powder basis, involve either membrane processing or ion exchange (Zydney, 1998; Doultani et al., 2003). Both methods result in considerable yield loss and so supercritical extraction was considered as an option for the removal of lipids.

Dairy complex lipid products produced by solvent extraction are available commercially (Fonterra, 2012). Supercritical extraction as an alternative to solvent extraction, was investigated to see if the defatted proteins could also be recovered in an undenatured state. In our study, spray dried Whey Protein Concentrate (WPC) powders have been extracted with both $\mathrm{CO}_{2}$ and DME but in both cases lipid yields were very low, indicating that the lipids are strongly bound to the whey proteins (Catchpole et al., 2007a). Liquid whey protein concentrates were also extracted by supercritical antisolvent fractionation using DME. It was found that high lipid yields could be obtained, but elevated temperatures of up to $333 \mathrm{~K}$ were required and the process resulted in some denaturation of protein. The process was also been used to extract High Fat Whey
Protein Concentrates (HFWPC) which already contain partly denatured proteins. The lipids are generally around $70 \%$ neutral and $30 \%$ phospholipids, consisting mainly of phosphatidylethanolamine (PE), phosphatidylcholine (PC), sphingomyelin (SM) and phosphatidylserine (PS) with lower levels of phosphatidylinositol (PI).

Supercritical antisolvent fractionation using DME produced a lipid yield of between 60 and $80 \mathrm{wt} \%$ of the lipids present (Catchpole et al., 2007a). Higher extraction yields were obtained with a HFWPC containing a higher $13.2 \mathrm{wt} \%$ lipid content (type A), while lower yields were obtained from powder with a $7.0 \mathrm{wt} \%$ lipid content made by a different process (type B). The residual non-extracted lipid levels were comparable for both feedstocks. The lowest extraction yield was for an acidified HFWPC feed stream which had a significantly higher viscosity. The effect of solids concentrations between 5 and $20 \mathrm{wt} \%$ was mixed, depending on the specific manufacturing process employed and the balance of proteins present. A comparison between the extract loading for egg lipids and for dairy lipids from HFWPC is shown in Fig. 10. The completeness of extraction is high when the lipid feed loading is low and declines at high lipid loadings. This may be due to neutral lipid solubility limitations in the DME + water solvent system. The solubility of neutral lipids in DME decreases with increasing water content, but the solubility of complex lipids is not affected, or in some cases even improves (Tallon and Catchpole, 2004). 


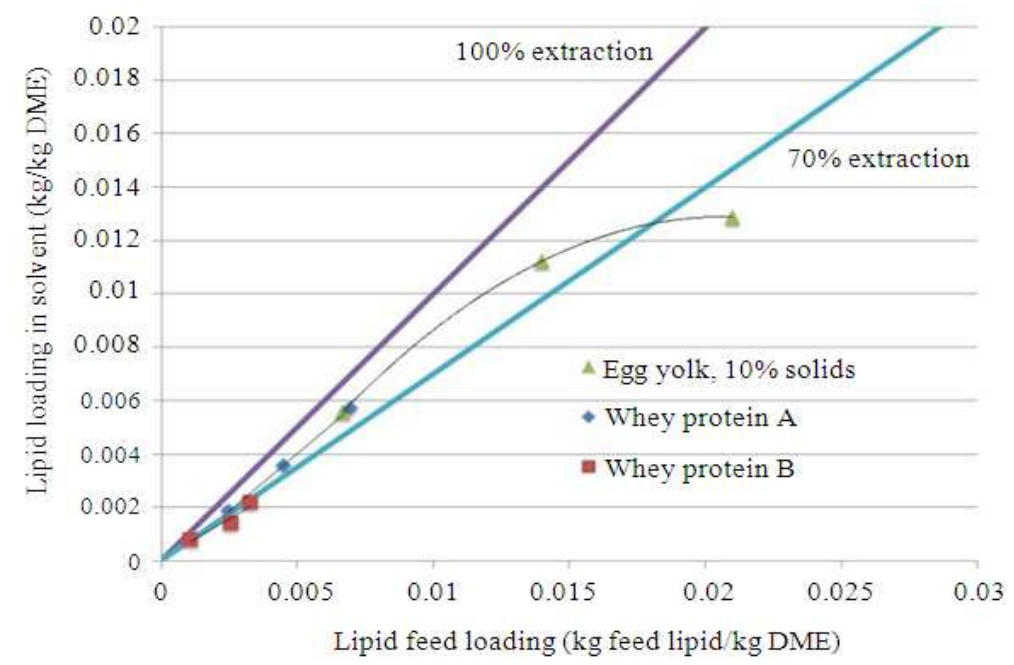

Fig. 10. Extraction of lipids from aqueous whey protein concentrates and egg yolk by co-current extraction with dimethyl ether

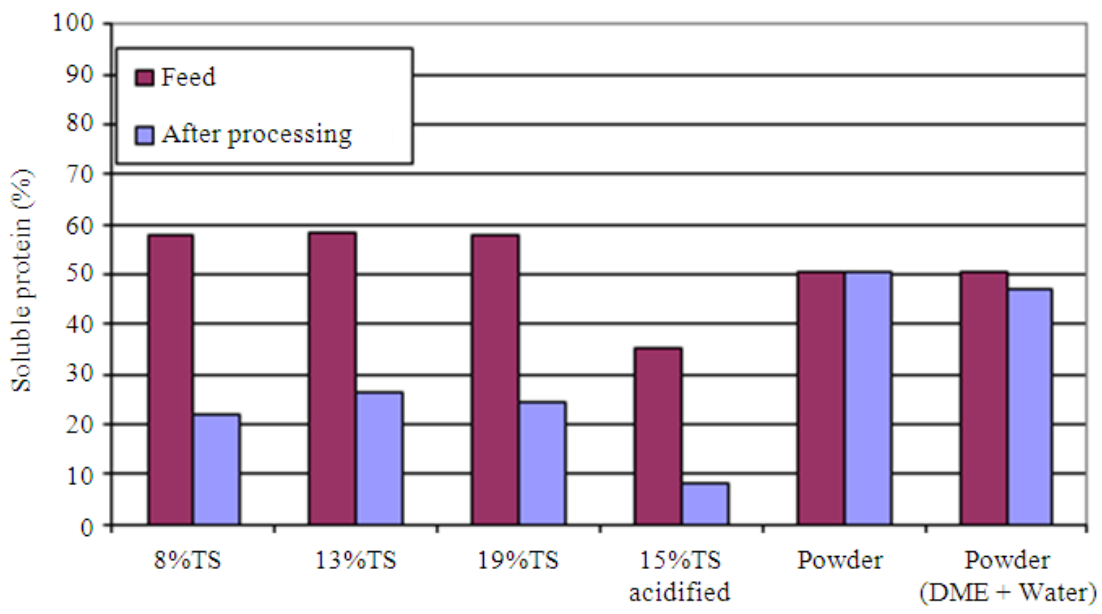

Fig. 11. Protein solubility before and after antisolvent processing of whey protein concentrate. TS = solids content by mass. Powder $=$ spray dried

The decline in extraction efficiency may also be due to mass transfer limitations due to the short contacting time in the static mixer. Packed countercurrent flow columns are an alternative to overcome contacting limitations, but precipitated proteins can cause fouling and flooding of the column. It is advantageous to use a short contact time, because precipitated protein can be continuously removed as long as it does not become excessively dehydrated (which occurs to a greater extent with longer contact time) whereas the protein collects in coprecipitated water in a co-current configuration and can be recovered in a raffinate stream. Analysis of the phospholipids in the extract by ${ }^{31} \mathrm{P}$ NMR (Mackenzie et al.,
2009) shows good extraction of all the main classes of phospholipid present, but with slightly better extraction of PC, PE and SM compared to PI and PS.

Decreases in the solubility of proteins were observed to varying degrees following antisolvent processing. For the dairy streams, which consist largely of whey proteins, changes in the percentage of soluble protein after processing are shown in Fig. 11 for type A reconstituted solutions. Also included for comparison are the changes in protein solubility for type A powder extracted with DME and DME + water as a co-solvent. There is a reduction in protein solubility for antisolvent runs (liquid feed) as shown in Fig. 11, but very little 
change following the extraction of powders, even when using water as a co-solvent with DME. Unfortunately, the extraction yield of lipids is also low from powders. It is predominantly the $\beta$-lactoglobulin and to a lesser extent, $\alpha$-lactalbumin that becomes denatured and thus insoluble after processing. These whey proteins are particularly affected when processing lower $\mathrm{pH}$ feeds.

Changes in the solubility of the freeze dried fresh egg yolk proteins have also been studied as a function of the water loading during processing (Tallon et al., 2005). The protein solubility of freeze dried yolks was measured to be $22 \%$ by mass. Extracting lipids from egg yolk directly with a DME antisolvent process gave solubilities between 7 and $19 \mathrm{wt} \%$ depending on the solids content in the feed and the processing temperature. A greater reduction in solubility was observed for higher processing temperatures and for runs where the amount of water in the system was close to the limit of the water solubility in DME. Processing with either a substantial excess of water, or with a shortage of water, results in a smaller degree of solubility reduction. Extraction of freeze dried powder gives very little reduction in protein solubility.

\section{PRODUCTION OF BIOMASS BY MICRO-ORGANISMS}

The ability of microorganisms (algae, bacteria, fungi and yeasts) to produce a wide range of biochemicals under controlled conditions is increasingly being recognized for its commercial potential. Microorganisms can produce large amounts of biomass rapidly, can metabolize and convert a wide range of feed materials from sugars through to carbon monoxide and can be engineered to produce high concentrations of specific target compounds. Microorganism derived consumer products are favourable to some sectors of the market as alternatives to animal derived products and the production process is sustainable compared to other feedstocks derived from wild harvest. Recovery of minerals and water is however important for full lifecycle sustainability. Target products are often medium to high value petrochemical replacements or bioactive compounds for dietary, cosmetic and pharmaceutical applications (Certik et al., 2012), although an increasing body of work is also targeted at low value, high volume, biofuel production from algae (Ratledge and Cohen, 2008; Yuan et al., 2011).

\subsection{Dietary Applications}

Dietary applications include production of lipids that are highly enriched in the unsaturated fatty acids eicosapentaenoic acid (EPA), docosahexaenoic acid (DHA), $\gamma$-linolenic acid (GLA) and arachidonic acid (ARA) (Ratledge and Cohen, 2008; Olaizola, 2003; Catchpoleet al., 2010; Wen and Chen, 2005; Mendes, 2008) and microorganisms that produce lipophilic pigments (Mendes, 2008; Catchpole et al., 2010; Krichnavaruk et al., 2008; Lim et al., 2002; Schonemann et al., 2008). The production of lipids from micro-organisms via industrial fermentation has been commercialized by Martek Biosciences Corporation and others for infant formula and other specialized dietary needs (Wynn and Ratledge, 2007).

An example from our work is the heterotrophic fermentations of a wild-type strain of the fungus Mortierella Alpina (MA) to produce lipids highly enriched in ARA. Figure 12 shows the fatty acid composition evolving during a 13 day growth period in a $250 \mathrm{~L}$ pilot scale fermentation during which palmitic and linoleic acids are converted primarily to ARA and to a small extent, EPA. At the end of the fermentation ARA makes up approximately $30 \%$ of total fatty acids.

The commercial scale extraction of lipids from fermentation systems has so far been limited to use of hexane (Wynn and Ratledge, 2007). The use of $\mathrm{CO}_{2}$ or $\mathrm{CO}_{2}+$ co-solvents for extraction has been investigated and has been reviewed by Mendes (2008); Wisniak and Korin (2005) and Catchpole et al. (2010). The challenges to successful commercial extraction of lipids include the high cost of fermentation, costly drying of the biomass before extraction for many solvent systems and difficulties obtaining a good yield. Poor yields are due to a combination of factors, including difficulties in breaking open dry cell walls and the cells containing complex lipids that are not soluble in non-polar solvents (Mendes, 2008; Catchpole et al., 2010). Extraction methods that avoid the need for drying such as sonication, enzymatic digestion, $\mathrm{pH}$ adjustment and high shear flows have been investigated with varying degrees of success.

To overcome the high costs of drying and the poor yields due to the form or type of lipid present, we have developed a processing technology using DME to extract wet biomass (Catchpole et al., 2010; 2007b). The extraction of lipids from wet MA biomass is shown in Fig. 13 and from freeze-dried biomass in Fig. 14, with comparison against $\mathrm{CO}_{2}$ extraction. The extraction of lipids from freeze-dried Mortierella species using supercritical fluids (Sako et al., 1989; Sakaki et al., 1990) and using $\mathrm{CO}_{2}$ (Dalai et al., 2011; Nisha et al., 2012) and organic solvents has been previously reported. 


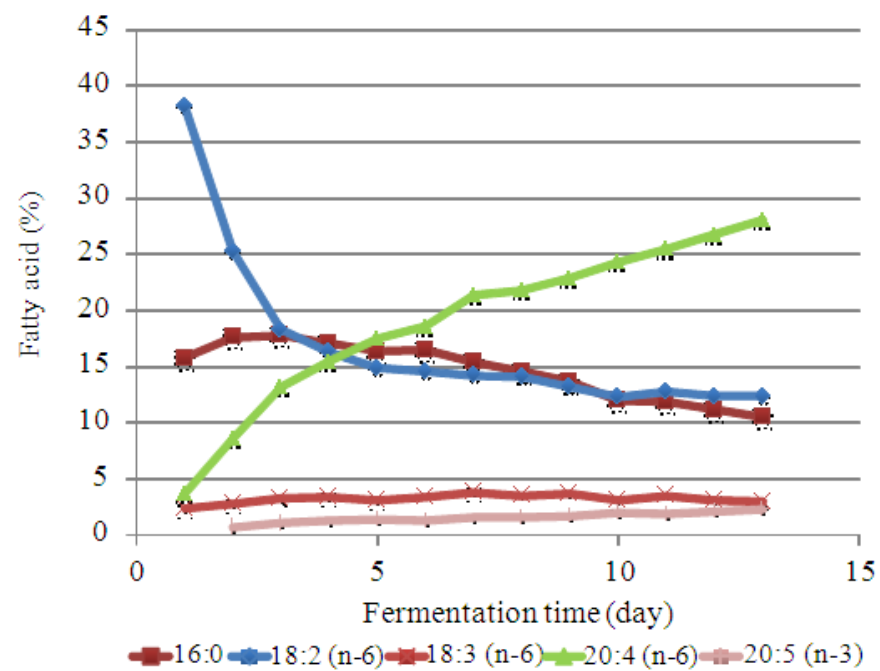

Fig. 12. Fatty acid composition of Mortierella alpina fermentation biomass as a function of fermentation time. Key to fatty acid type: 16:0 = palmitic acid; 18:2 = linoleic acid; 18:3 $(n-6)=\gamma$-linolenic acid; 20:4 $(n-6)=$ arachidonic acid; $20: 5(n-3)=$ eicosapentaenoic acid

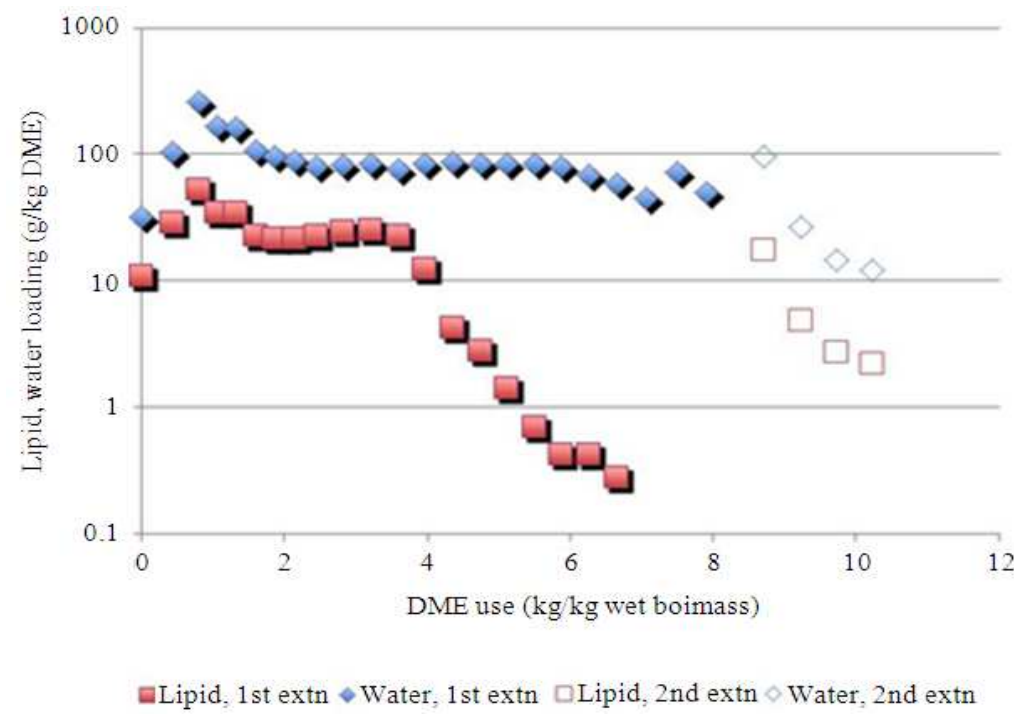

Fig. 13. Lipid and water loadings in DME from the extraction of wet Mortierella alpina biomass as a function of DME usage for two stages of extraction

The batch extraction of water from a bed of MA with DME takes place under almost steady state conditions, as shown in Fig. 13, whereas the extraction of lipids is steady for a period until a point where the rate drops off. Inspection of the residual bed of material revealed significant bypassing and aggregation of the bed into wet patches (poorly extracted) and dry patches (complete extraction).
A secondary extraction after repacking the bed of material resulted in near-complete extraction of the remaining lipids, Fig. 13. The poor extraction behaviour from the bed is at least partly explained by the coating of biomass with 'sticky' carbohydrates. These tend to cause clumping and aggregation and a barrier to mass transfer. The benefits of pre-processing of biomass by enzymatic or chemical methods to remove this sticky exudate and 
improve extraction are discussed later in this study. In contrast, freeze-drying of the biomass gives a porous structure in which the lipids are easily accessible to the solvent. Extraction of freeze dried powder using DME gives almost complete lipid extraction using around $2 \mathrm{~kg}$ DME/kg dry biomass, shown in Fig. 14 (square symbols), with minimal additional extraction after this point. In contrast, more than $40 \mathrm{~kg} \mathrm{CO} / \mathrm{kg}$ dry biomass is required to extract all the neutral lipids (diamonds). Dalai et al. (2011) also reported low $\mathrm{CO}_{2}$ yields compared with solvent extraction.

The residual biomass after $\mathrm{CO}_{2}$ extraction was reextracted with DME to give a complex lipid-rich extract Fig. 14 (triangles). The extraction yields are higher using DME than using $\mathrm{CO}_{2}$ and the yield is close to the total quantity of lipid present measured by exhaustive chloroform/methanol extraction. The higher yield using DME is largely due to the extraction of both neutral and complex lipids. The solubility of lipids in DME is also substantially higher than in $\mathrm{CO}_{2}$ and extractions are more rapid.

\subsection{Biofuel Applications: Extraction of Butanol from Fermentation Broth}

An example of a liquid biofuel application is the production of biobutanol by Clostridium bacteria. 1-Butanol is widely used in the production of butyl acrylate and methacrylate and is also added to plastics, hydraulic fluids and detergent formulations (EPA, 1994). More recently it has been recognised as a potential biofuel (Jin et al., 2011; Ranjan and Moholkar, 2012). It has a high energy content and can be directly used in internal combustion engines, is less volatile and explosive and has a lower vapour pressure (Garcia et al., 2011; Ranjan and Moholkar, 2012) than ethanol. The Acetone-Butanol-Ethanol (ABE) fermentation process using Clostridium bacteria allows production of biobutanol from renewable, low cost lignocellulosic biomass, with an $\mathrm{A}: \mathrm{B}: \mathrm{E}$ ratio of $3: 6: 1$ and a typical butanol concentration around $12 \mathrm{~g} \mathrm{~L}^{-1}$ (Kumar and Gayen, 2011). The butanol production level is selflimiting, as it is toxic to the microorganism above these levels. Distillation is the traditional method to recover butanol from the fermentation broth, but several alternatives have also been investigated (Oudshoorn et al., 2009). The high pressure phase equilibrium of butanol: $\mathrm{CO}_{2}$ (Secuianu et al., 2004; Chen et al., 2002) and butanol:water: $\mathrm{CO}_{2}$ (Panagiotopoulos and Reid, 1986; Chen et al., 2002; Winkler and Stephan, 1997) have been reported, indicating that butanol extraction from fermentation broth could be feasible. Over $99 \%$ separation of butanol from a $5 \mathrm{wt} \%$ butanol feed has been reported using $\mathrm{CO}_{2}$ in a mechanically agitated Oldshue-Rushton column (Laitinen and Kaunisto, 1999).

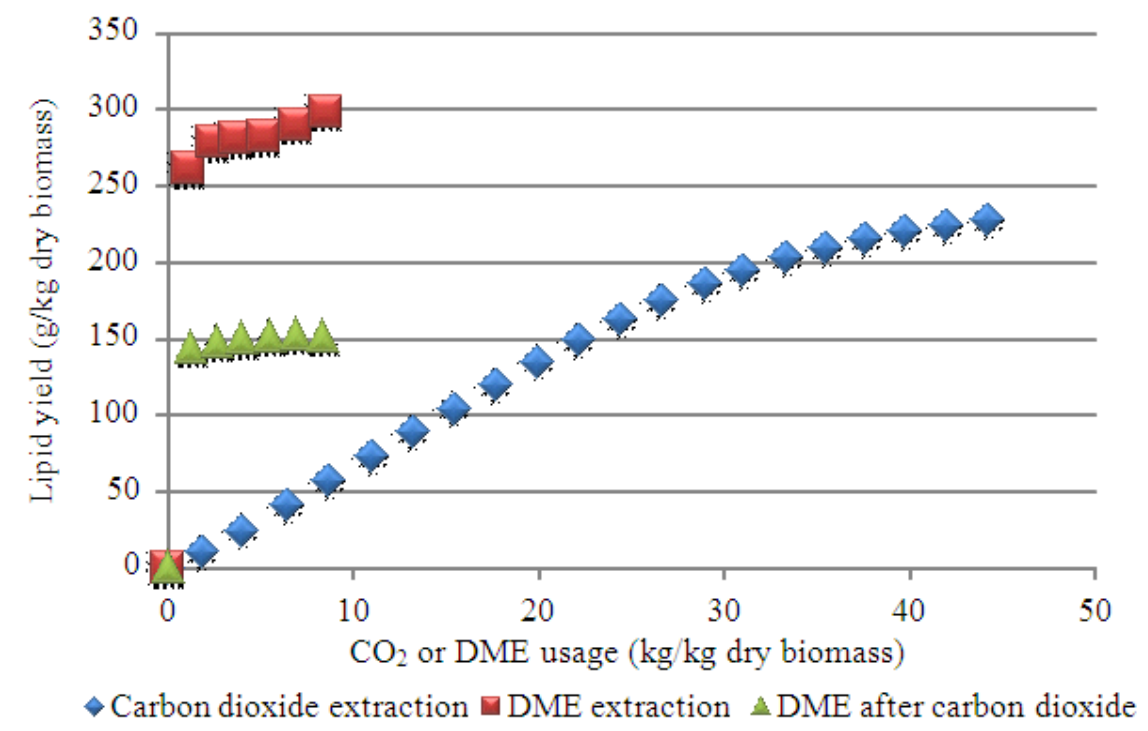

Fig. 14. Lipid yield from the extraction of freeze-dried Mortierella alpina as a function of dimensionless solvent usage. Symbols: diamond $=$ extraction of MA with $\mathrm{CO}_{2}$ at 300 bar, $313 \mathrm{~K}$; squares = extraction of MA with DME at 40 bar and $316 \mathrm{~K}$; triangles $=$ re-extraction of residues after $\mathrm{CO}_{2}$ extraction with DME at 40 bar and $317 \mathrm{~K}$ 


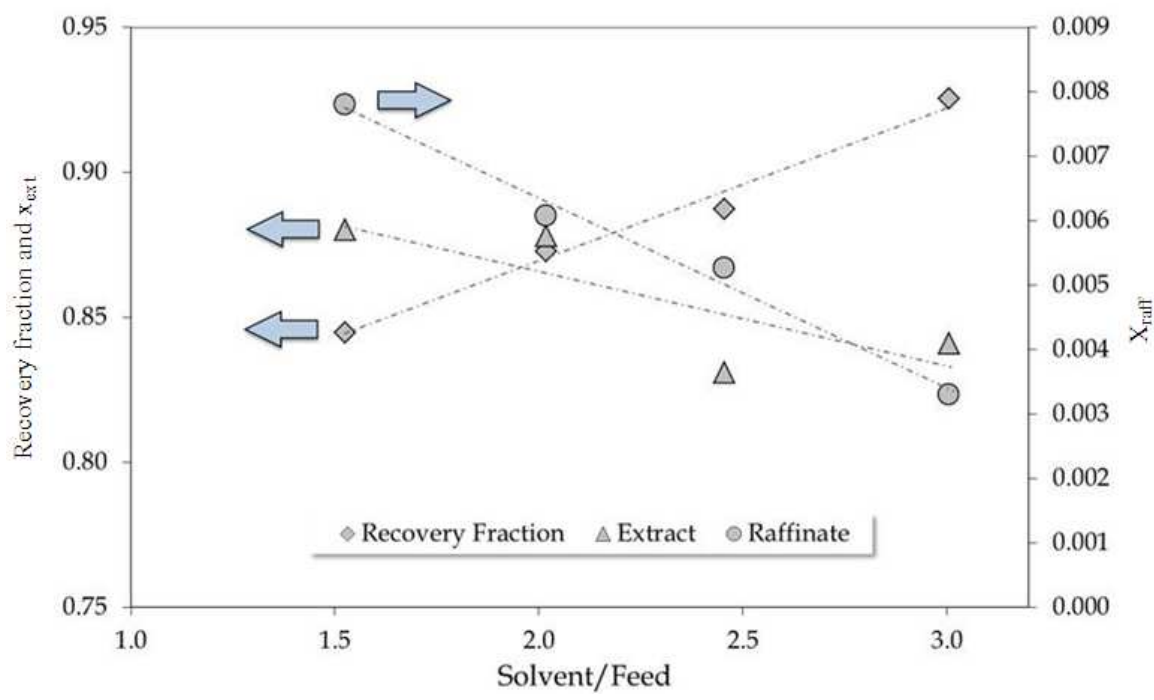

Fig. 15. Composition of raffinate and extract, and recovery fraction of 1-butanol, for different $\mathrm{CO}_{2}$-to-feed ratios and $5 \mathrm{w} \%$ concentration of 1-butanol in the feed. Pressure 100 bar

We have carried out $\mathrm{CO}_{2}$ extraction of model 1-butanol solutions and actual ABE fermentation broths using a fully recycled $\mathrm{CO}_{2}$ flow. Figure 15 shows the percentage of feed butanol recovered and the butanol concentration in extract and raffinate after separation of a $5 \mathrm{wt} \%$ butanol solution in a countercurrent flow column (20 mm ID, $1200 \mathrm{~mm}$ length, $16 \mathrm{~mm}$ diameter Pall ring packing) operated at 100 bar and $40^{\circ} \mathrm{C}$. Recovery of butanol was better at higher solvent to feed ratios, as expected for a stripping operation, but greater quantities of water were also co-extracted resulting in a lower butanol concentration in the extract. The extract however is still substantially enriched, up to $90 \%$ butanol and the residual water could be removed by conventional drying methods. Results obtained without the Pall ring packing were similar indicating no added benefit was obtained in this case. Smaller packing with a higher surface area was also tested but had a flooding limit lower than the minimum flow rate we could operate on the equipment used.

A trial biobutanol solution was produced by anaerobic fermentation in a $20 \mathrm{~L}$ bioreactor using Clostridium acetobutylicum ATCC 824. Temperature was controlled at $37^{\circ} \mathrm{C}$ and the broth harvested after 68 h. After centrifuging the solid biomass was discarded. The broth contained a 1-butanol concentration of 1.2 $\mathrm{wt} \%$. After separation using $\mathrm{CO}_{2}$ as described above, $82 \%$ recovery of butanol was achieved, with a concentration in the extract of $72 \mathrm{wt} \%$.

\section{PRE-PROCESSING BY PHYSICAL, CHEMICAL OR ENZYMATIC REACTION}

Many plant, animal and microbial-based feed materials contain relatively low levels of desired bioactives such as phospholipids and glycolipids, flavours and fragrances, pigments, flavonoids and correspondingly large amounts of water and also carbohydrates that may hinder supercritical extraction. Generally, $\mathrm{CO}_{2}$ extraction cannot be used on biomasses containing high amounts of water, due to the immiscibility of water and $\mathrm{CO}_{2}$ and so the processing strategy is to first dry and grind the biomass to a small particle size and then carry out supercritical extraction. Recently, we and others have been investigating the use of pre-treatment processes to increase the yield of bioactives in the feed material by reducing the amount of non-extractable material. These processes include enzyme pre-processing (using proteases, carbohydrases) and acid-base treatments. Enzymes can also be used to convert lipids to free fatty acid or ester forms to make them more easily extractable, or to cleave selected fatty acids and enable fractionation of fatty acids and transesterification reactions to be carried out. These processes can lend themselves to supercritical extraction either post reaction, or even in situ. 


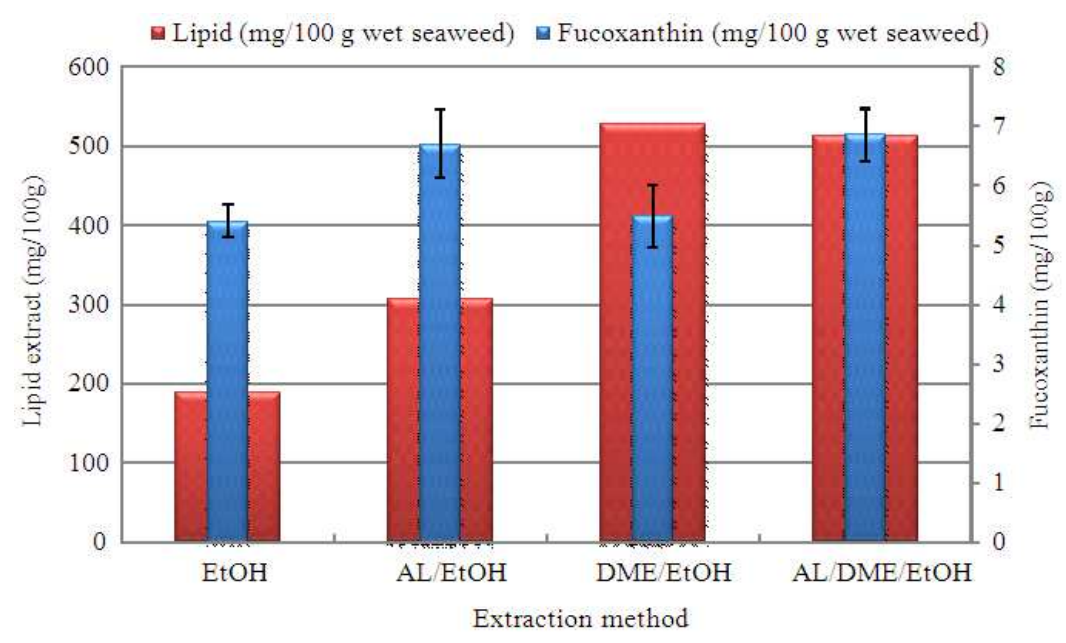

Fig. 16. Extraction of lipids and fucoxanthin from Undaria Pinnatifida seaweed with different methods. EtOH-ethanol extraction (90\% ethanol); AL/EtOH-alginase treatment followed by ethanol extraction ( $90 \%$ ethanol); DME/EtOH-dimethylether extraction with $10 \%$ ethanol co-solvent; $\mathrm{AL} / \mathrm{DME} / \mathrm{EtOH}$-alginase treatment followed by dimethylether extraction with $10 \%$ ethanol co-solvent

\subsection{Size Reduction}

Drying and/or milling of feed materials are simple and widely used pre-processing operations, but the importance of these steps to the success of downstream processing is sometimes overlooked, leading to inefficient use of processing plant, handling difficulties, or changes in product composition or stability.

The effect of particle size on the extraction rate of solid substrates is complex, depending also on the quantity and distribution of extractable material, as well as variations in density, porosity and composition of the non-extractable matrix (Mukhopadhyay, 2000). Extractions using $\mathrm{CO}_{2}$ often have an initial period of constant solubility limited extraction, due to the high diffusivity of $\mathrm{CO}_{2}$ compared to liquid solvents and the relatively low solubility of solutes in $\mathrm{CO}_{2}$. After this initial period, extraction may become mass transfer limited and it is important to have a sufficiently small particle size to avoid a long extraction 'tail'. The effect of particle size on yield and extraction time has been reported for sage leaf, coriander and celery seed (Catchpole et al., 1996; 1997) and Totara wood (Catchpole et al., 2003). Mukhopadhyay (2000) observed that particle size less than about $0.3 \mathrm{~mm}$ was sufficient for good extraction from a selection of plant materials.

For materials with a hard shell or epithelium it can also be useful to break this by milling, or other means, to improve solvent access to the substrate. Conversely it is also important not to reduce the particle size more than necessary. This can lead to unnecessary handling difficulties or an increase in pressure drop that limits the overall capacity of processing plant.

The choice of milling operation depends on the material to be milled. High oil content materials, such as some seeds, are more suited to low shear rolling or crushing. Soft plant materials can also be processed in a low shear device including mincers and juicers unless, like microalgae or ova, they have natural small scale barriers that require a high shear rate to break, in which case jet milling or a mill with a cutting blade may be suitable. In some cases milling may be combined with a chemical treatment. Harder materials, or materials with low moisture or oil content, are well suited to blade or impact mills.

\subsection{Enzymatic Pretreatment of Macroalgae}

An exemplar process is described below for the pretreatment of a macro-algae, Undaria pinnatifida using an enzyme, followed by extraction of fucoxanthin using either ethanol or DME. Undaria pinnatifida is a seaweed that grows naturally in Japan (known as Wakame) but is an invasive species in New Zealand and Australia. It produces the valuable lipophilic pigment fucoxanthin and also a small amount of lipids rich in Steariodonic Acid (SDA) (C18:4 n-3) and EPA. Roh et al. (2008) have investigated the extraction of fucoxanthin from Undaria pinnatifada using $\mathrm{CO}_{2}$ and co-solvent. Enzymatic pre-treatment to improve the yield of fucoxanthin from Undaria in an ethanol extraction process has been 
investigated (Sho and Sugiyama, 2010), but this has not been combined with supercritical fluid extraction.

The use of enzymes to assist the extraction and recovery of bioactives from seaweeds has been reviewed in detail by Wijesinghe and Jeon (2012). The alginase lyase enzyme selected for this work hydrolyses specific polysaccharides containing $\beta$-D-mannuronate residues in seaweed cell walls. The effects of $\mathrm{pH}$, reaction temperature, enzyme to feed ratio and reaction time on fucoxanthin yield were investigated for their effect on fucoxanthin stability. The incubation time and temperature were the most important parameters. Typical enzyme pre-treatment conditions were $5 \%(\mathrm{w} / \mathrm{v})$ solids, $\mathrm{pH} 6.2$, reaction temperature of $37^{\circ} \mathrm{C}$, reaction time of 2 $\mathrm{h}$ and $0.05 \mathrm{wt} \%$ enzyme using continuous mixing. Water soluble hydrolysis products from the reaction were separated from the residual seaweed biomass by centrifugation at $6000 \mathrm{~g}$ for $20 \mathrm{~min}$. Removal of the hydrolysis products improved the recovery of lipids and fucoxanthin and also reduced the amount of residual biomass that needed to be processed by around $40-50 \%$ prior to extraction.

Yields for unprocessed and enzyme processed feed material are shown in Fig. 16 and images of the processed seaweed fractions are shown in Fig. 17. Alginase pre-treatment increased the total lipid yield and yield of fucoxanthin for extraction with either ethanol or liquid DME. The DME extraction runs shown here were carried out using a packed bed extraction and, 10\% ethanol co-solvent was used to help maintain a uniform extraction bed throughout the extraction.

The enzyme pre-treatment, followed by removal of the aqueous phase containing water soluble compounds, reduced by $50 \%$ the mass of material that required further processing. The water soluble material contained some lipids (10-15\% of total lipids in the seaweed) but a negligible amount of fucoxanthin. The enzyme pretreatment improves the overall lipid yield by $>10 \%$ and fucoxanthin yield by $>20 \%$.
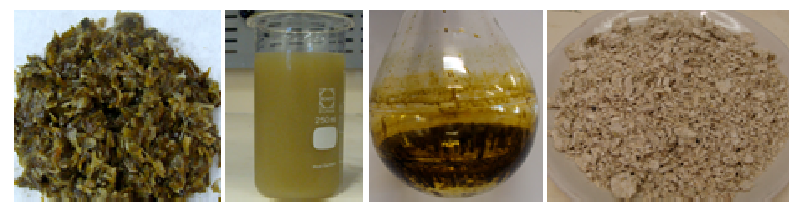

Fig. 17. Photos of seaweed extraction process. From left: close-up of wet, chopped seaweed; aqueous phase after enzyme treatment; crude extract from DME + EtOH cosolvent extraction; residual biomass after extraction
DME extraction with an ethanol co-solvent extracts some non-lipid material. Without enzyme pre-treatment the non-lipid material was approximately $50 \%$ of total extract. Ethanol solvent extracts contained even higher amount of non-lipid materials. After enzyme pretreatment the non-lipid content reduced to $<20 \%$ for DME+ethanol co-solvent extraction.

\section{IN SITU PROCESSES}

The controllable density and mass transport properties of supercritical fluids lend themselves well to fully integrated reaction and adsorption processing using the supercritical fluid as the primary processing medium. Carrying out chemical reactions, for example enzymatic hydrolysis, under supercritical conditions allows continuous stripping of any soluble reaction products that are produced. Adsorption and/or desorption processing is aided by low fluid viscosity which allows high flow through packed beds of particles without excessive pressure drop. In some cases a switch between sorption and desorption conditions can be induced simply by changing the operating pressure or temperature.

\subsection{Supercritical Fluid Phase Chromatography}

Supercritical chromatography is now an accepted method for the analysis of a wide range of raw materials, particularly lipophilic drug candidate molecules including enantiomeric isomers. Analytical scale chromatography is reviewed in detail elsewhere (Taylor, 2009) and is not covered here.

Supercritical chromatography also has great potential for preparative separations. The benefits over conventional liquid chromatography include the significant reduction in pressure drop that can be achieved because of the low viscosity of the solvent, meaning that higher surface area stationary phases can be used and/or higher solvent and product throughput achieved. Disadvantages of supercritical chromatography at a production scale include some limitations in options for on-line detection and the high overall capital costs for high pressure processing equipment.

Some studies on the separation of high value polyunsaturated ethyl esters, particularly EPA and DHA with supercritical fluid chromatography have been carried out. Perrut et al. (1998) achieved EPA and DHA fractions with a purity of $92 \%$ and $85 \%$, respectively and yields of $99 \%$ starting from a feed material containing 
50\% EPA and 30\% DHA. Higashidate et al. (1990) used a silver nitrate-loaded silica gel column at a laboratory scale to separate fatty acid extracts from the $\mathrm{CO}_{2}$ extract of esterified sardine oil and obtained EPA and DHA-rich fractions with purities of $93 \%$ and $82 \%$, respectively. Nilsson et al. (1988) used pressure and temperature gradients for fractionation of urea-crystallized fish oil ethyl esters to recover $85 \%$ of the EPA and DHA from the feed with $90 \%$ purity. Snoey-Elich (2001) was also able to concentrate fish oil EPA ethyl esters from a purity of $50 \%$ to $>95 \%$. This was achieved using an industrial column of porous silicon dioxide impregnated with (3-aminopropyl)-triethoxysilane as the stationary phase. The economic feasibility of producing industrialscale quantities of EPA and DHA using SFC was investigated by Alkio et al. (2000). Pettinello et al. (2000) carried out pilot scale trials using quantities of feed materials on the order of hundreds of grams and achieved a $93 \%$ pure EPA rich fraction at $25 \%$ yield. So far the only known commercial scale operation to produce highly pure ethyl esters is carried out by KDPharma (2012).

We have carried out a range of optimisation studies at semi-preparative scale to evaluate a range of proprietary column packings and operating conditions, for separation of EPA and DHA from marine and algal oils (Montanes et al., 2012), juniperonic acid from Biota orientalis seed oil and xymenynic acid from Sandalwood seed oil. Oils were first converted to ethyl esters or free fatty acids before being loaded at levels of approximately $100-1000 \mu \mathrm{L}$ on columns with approximately $50 \mathrm{~g}$ of silica. We have been able to achieve $>95 \%$ separation and good recovery in most cases using $\mathrm{CO}_{2}$ without cosolvent and with both modified and unmodified silica.

More recently we have commissioned a pilot plant, shown in Fig. 18, holding up to 4 by $10 \mathrm{~L}$ columns, up to 4 separation stages, on-line UV absorbance measurement and supercritical or liquid mobile phase flow rates up to $100 \mathrm{~kg} \mathrm{~h}^{-1}$. The plant is mobile and rated for use with flammable solvents. Results for trial separation of fish oil ethyl esters using a coarse grade of normal phase silica (60-200 $\mu \mathrm{m})$ are shown in Fig. 19. EPA and DHA peaks are not completely separated in this example, but reasonable concentration of EPA was still able to be achieved using relatively coarse silica.

We are also investigating the isolation and purification of a range of other highly unsaturated fatty acids and the fractionation of complex lipids and other polar compounds.

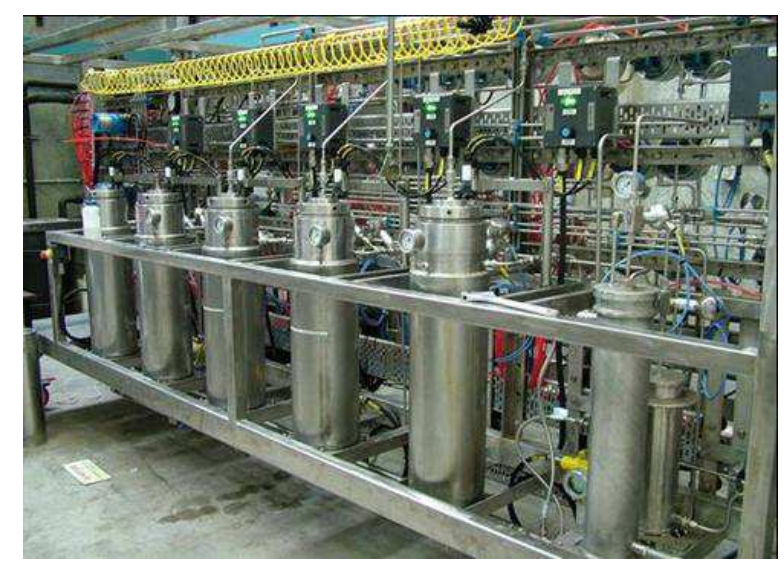

Fig. 18. Photo of 4 by $5 \mathrm{~kg}$ column mobile pilot plant recently commissioned

\subsection{PUFA Enrichment by Selective Fatty Acid Esterification}

Fish oil and more recently microalgae, have been the traditional source for EPA and DHA, with PUFA usually found as triglycerides (TAG) and mainly located at the sn-2 position of the glycerol backbone (Ando et al., 1992). Vegetable oils such as borage, evening primrose or blackcurrant seed oils are particularly rich in $\gamma$-Linolenic Acid (GLA, 18:3 n-6), which is preferentially located at the sn-2 and to a lesser extent in the sn-3 positions (Lawson and Hughes, 1988). Several options are available to obtain PUFA concentrates (Rubio-Rodriguez et al., 2010; Eltringham and Catchpole, 2008), but the use of specific enzymes, i.e. lipases, has attracted attention recently due to their high stereospecific activity and the mild reaction conditions they require, which prevents degradation of the highly labile oils. These position specific enzymes are commercially available in free or immobilized form and have a high regiospecificity for the sn-1 and sn-3 positions of the glycerol backbone, which allows the enrichment of PUFA in the sn-2 position either by hydrolysis (Linder et al., 2002) or by transesterification processes (Munio et al., 2008; Haraldsson et al., 1997).

By adjusting extraction conditions, supercritical $\mathrm{CO}_{2}$ allows selective removal of the Free Fatty Acids (FFA) or Fatty Acid Ethyl Esters (FAEE) produced in the enrichment enzymatic reaction, leaving a PUFA enriched partial glyceride fraction in the raffinate. It is also possible to carry out the enzymatic reaction under $\mathrm{CO}_{2}$ conditions (Knez, 2009) and the reaction step can be easily integrated with the extraction post-processing, minimizing the number of handling and processing steps and limiting degradation of both the oil and the enzyme itself. 


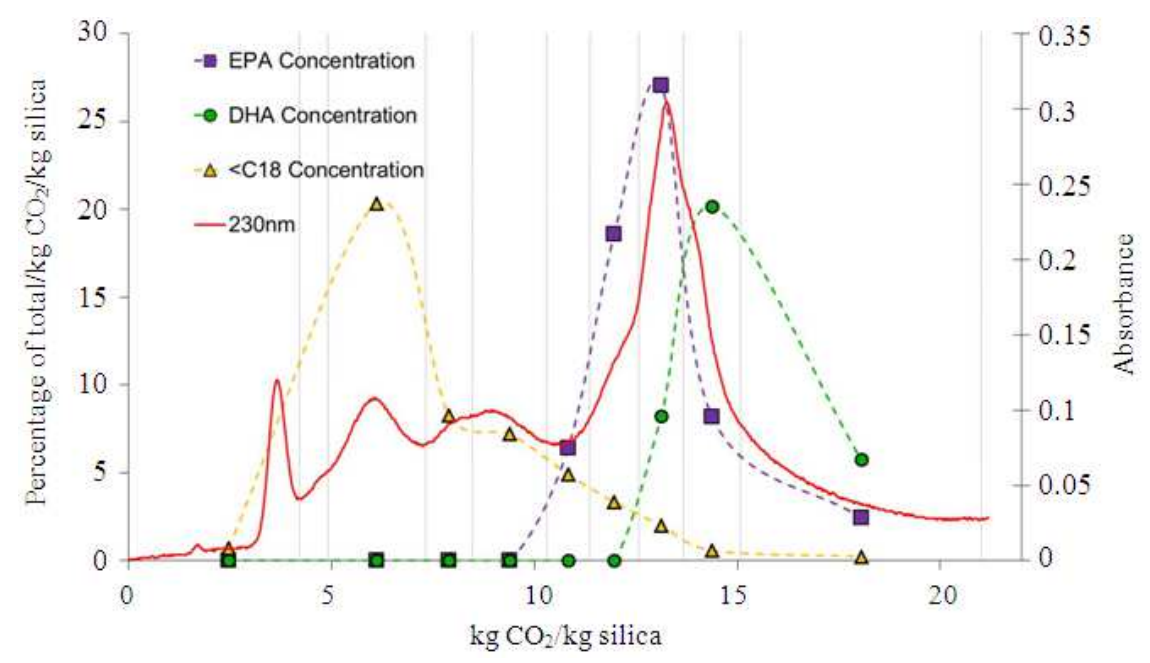

Fig. 19. Separation of fish oil ethyl esters on a $5 \mathrm{~kg}$ silica column using $\mathrm{CO}_{2}$ at 170 bar. Red line shows absorbance at $230 \mathrm{~nm}$. Dotted lines show recovery of EPA, DHA, and fatty acids $<\mathrm{C} 18$, as measured by gas chromatography from samples taken during the run

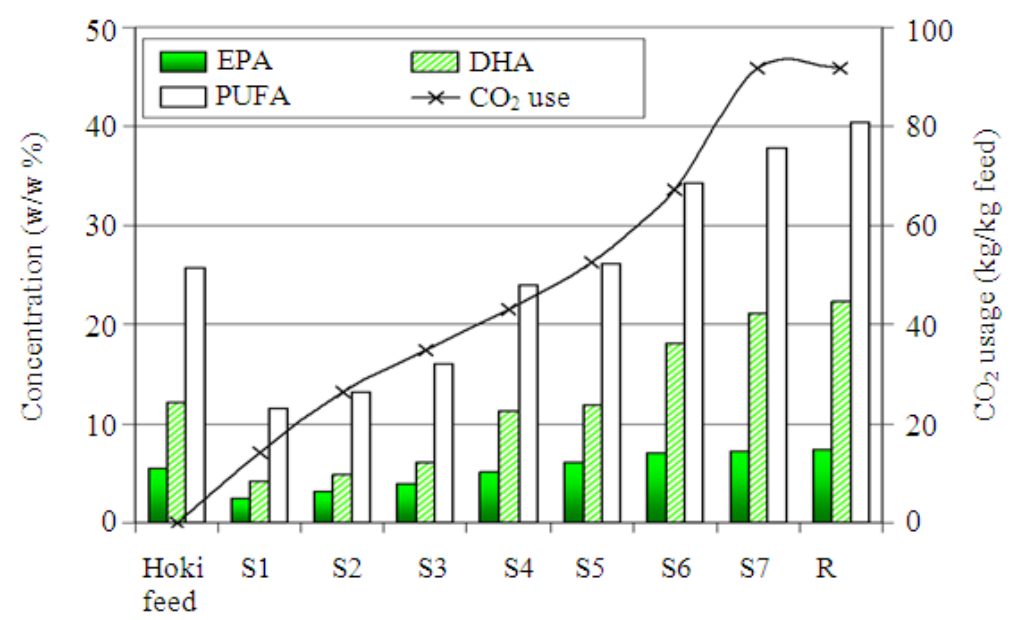

Fig. 20. EPA, DHA and total PUFA profiles of the feed oil, Separator (S) and Raffinate (R) fractions from stirred tank processing of hoki liver oil. Reaction conditions: 3:1 ethanol:oil molar ratio, 1:10 enzyme:oil weight ratio

Enzymatic reactions in supercritical fluids often show higher reaction rates than those carried out under classical conditions due to favourable mass transfer kinetics (Knez, 2009). An in situ supercritical fluid extraction process allows continuous transesterification with immediate product recovery and may help drive the reaction to completion.

We have carried out enrichment of PUFA from refined hoki liver oil using both a stirred tank and a packed column method at $40^{\circ} \mathrm{C}$ (Vagi et al., 2009; Weber et al., 2008). Figure 20 shows the lipid composition of different fractions from a batch experiment in which Hoki liver oil was esterified using Lipozyme ${ }^{\circledR}$ RM-IM (NovozymesA/S, Denmark) under $\mathrm{CO}_{2}$ conditions at 150 bar in a stirred reactor. $\mathrm{CO}_{2}$ and ethanol were continuously passed through the reactor and the extracts (S1 to S5) contained the highly soluble fatty acid ethyl esters from the sn- 1 and sn-3 positions which are concentrated in saturated fatty acids. Further extraction at 300 bar (S6 and S7) was then carried out to recover the partial glycerides from the reaction. This fraction is enriched in EPA and DHA as shown in Fig. 20. 
The residual raffinate fraction also contains partial glycerides as well as unreacted triglyceride and is enriched in EPA and DHA. Fractions S6, S7 and R contained enhanced levels of DHA and total PUFA over the feed (1.8 and 1.6 fold increase for DHA and total PUFA, respectively) and a small enrichment in EPA.

The high solvent usage required ( $92 \mathrm{~kg} \mathrm{CO} / \mathrm{kg}$ oil), is not practical for industrial scale-up and we have further investigated a semi-continuous, packed column method, which produced a $>60 \%$ PUFA product and a FAEE rich byproduct ( $>95 \%$ ) using only one-fourth of the solvent required in the stirred tank experiments. Moreover, no deactivation was observed after 9 cycles of packed column processing and it is believed that keeping the enzyme under a $\mathrm{CO}_{2}$ atmosphere can help prevent enzyme deactivation.

The enrichment of borage seed oil was also studied using the packed column method, obtaining a GLA content in the PUFA rich fraction of $35-40 \%$ (cf. $20 \%$ in the feed). Ethanol-to-oil ratios up to 9 were studied and no detrimental effect was observed on enzymatic conversion or GLA content. Continuous flow pilot trials were carried out in a $2 \mathrm{~L}$ enzyme packed bed, during which an oil mass of greater than 60 times the mass of enzyme was processed over a period of several days. Consistent enrichment and no significant loss of enzyme activity during processing was observed. Conversion of triglycerides was greater than $80 \%$ throughout the run.

\section{CONCLUSION}

General awareness and understanding of supercritical and liquefied gas processing technology is increasing, as is understanding of where this technology best fits for processing of a wide range of emerging biological products. This awareness is being matched by an increase in industrial processing capacity and it is becoming increasingly viable to consider a pressurized solvent extraction process as a standard unit operation in development of new products and processes.

The integrated processing operations described here are some examples of the range of processing opportunities that are being investigated, or are yet to be fully developed, but they give an indication of some important emerging trends. In particular, the use of microbiological systems for the primary production of chemicals has much promise for high volume sustainable production of dietary, medical and biochemical products. Associated with this is the need for development of efficient processes for separation of organic compounds from dilute aqueous systems and for the isolation and concentration of target compounds. Also of increasing importance is for products to be formulated for efficacy and stability. In all of these areas supercritical fluid processing should be investigated, along with other processing alternatives, to determine the most favourable overall integrated process.

\section{REFERENCES}

Alkio, M., C. Gonzalez, M. Jantii and O. Aaltonen, 2000. Purification of polyunsaturated fatty acid esters from tuna oil with supercritical fluid chromatography. J. Am. Oil Chem. Soc., 77: 315-321. DOI: 10.1007/s11746-000-0051-3

Ando, Y., K. Nishimura, N. Aoyanagi and T. Takagi, 1992. Stereospecific analysis of fish oil triacyl-snglycerols. J. Am. Oil Chem. Soc., 69: 417-424. DOI: 10.1007/BF02523923

Catchpole, O. J., J. B. Grey and B. M. Smallfield, 1996. Near critical extraction of sage, celery and coriander seed. J. Supercritical Fluids, 9: 273-279. DOI: 10.1016/S0896-8446(96)90058-3

Catchpole, O., J. Ryan, Y. Zhu, K. Fenton and J. Grey et al., 2010. Extraction of lipids from fermentation biomass using near-critical dimethylether. J. Supercritical Fluids, 53: 34-41. DOI: 10.1016/j.supflu.2010.02.014

Catchpole, O.J. and S.J. Tallon, 2006. Process for separating lipid materials. NZ571454, WO2007123424.

Catchpole, O.J., A.N. MacKenzie and J.B. Grey, 2002. Separation technology. US7709668; WO03089399 A1.

Catchpole, O.J., B.M. Smallfield, P.J. Dyer, J.B. Grey and C. McNamara et al., 2004a. Processing of fresh, partially dewatered herbs with near-critical fluids. Proceedings of the 7th Italian Conference/9th European Meeting on Supercritical Fluids and Their Applications, Trieste, Italy.

Catchpole, O.J., J.B. Grey, K.A. Mitchell and J.S. Lan, 2004b. Supercritical antisolvent fractionation of propolis tincture. J. Supercritical Fluids, 29: 97-106. DOI: $10.1016 / \mathrm{S} 0896-8446(03) 00033-0$

Catchpole, O.J., J.B. Grey and B.M. Smallfield, 1997. Extraction of sage and coriander seed using nearcritical carbon dioxide. ACS Symp. Series 670: 7689. DOI: $10.1021 / \mathrm{bk}-1997-0670 . c h 006$

Catchpole, O.J., J.B. Grey, A.N. Mackenzie and D.R. Mende, 2003. Extraction of antimicrobial compounds from wood using supercritical $\mathrm{CO}_{2}$. Proceedings of 6th International Symposium on Supercritical Fluids, Apr. 28-30, Versailles, France. 
Catchpole, O.J., N.E. Durling and J.B. Grey, 2006. Improvements in or relating to separation technology. NZ545146, WO2007091901.

Catchpole, O.J., S.J. Tallon, J.B. Grey, K. Fenton and K. Fletcher et al., 2007a. Extraction of lipids from aqueous protein-rich streams using near-critical dimethylether. Chem. Eng. Technol., 30: 501-510. DOI: 10.1002/ceat.200600351

Catchpole, O., J. Grey, A. Mackenzie and S. Tallon, 2007b. Extraction of highly unsaturated lipids with liquid dimethyl ether.

Catchpole, O.J., S.J. Tallon, J.B. Grey, K. Fletcher and A.J. Fletcher, 2008. Extraction of lipids from a specialist dairy stream. J. Supercritical Fluids, 45: 314-321. DOI: 10.1016/j.supflu.2008.01.004

Catchpole, O.J., S.J. Tallon, P.J. Dyer, J.S. Lan and B. Jensen et al., 2005. Solubility measurement and modelling of urea in supercritical $\mathrm{CO}_{2}$ and $\mathrm{CO}_{2}+$ ethanol mixtures. Fluid Phase Equilibria, 237: 212218. DOI: 10.1016/j.fluid.2005.09.004

Catchpole, O.J., S.J. Tallon, W.E. Eltringham, J.B. Grey and K.A. Fenton et al., 2009a. The extraction and fractionation of specialty lipids using near critical fluids. J. Supercritical Fluids, 47: 591-597. DOI: 10.1016/j.supflu.2008.10.008

Catchpole, O.J., N.E. Durling, J.B. Grey, W. Eltringham and S.J. Tallon, 2009b. Supercritical antisolvent fractionation of plant extracts. In: Current Trends of Supercritical Fluid Technology in Pharmaceutical, Nutraceutical and Food Processing Industries, Duarte, A.R.C. (Ed.), Bentham Science Publishers, Sharjah, United Arab Emirates, ISBN-10: 1608050467, pp: 71-79.

Certik, M., Z. Adamechova and K. Laoteng, 2012. Microbial production of $\gamma$-linolenic acid: Submerged versus solid-state fermentations. Food Sci. Biotechnol., 21: 921-926. DOI: 10.1007/s10068012-0121-2

Chattopadhyay, P. and R.B. Gupta, 2002. Supercritical $\mathrm{CO}_{2}$-based production of magnetically responsive micro and nanoparticles for drug targeting. Indus. Eng. Chem. Res., 41: 6049-6058. DOI: 10.1021/ie020205b

Chen, H.I., H.Y. Chang and P.H. Chen, 2002. Highpressure phase equilibria of carbon dioxide +1 butanol and carbon dioxide + water +1 -butanol systems. J. Chem. Eng. Data, 47: 776-780. DOI: $10.1021 / \mathrm{je} 010237 \mathrm{q}$
Dalai, A.K., A. Tilay, R. Azargohar, U. Annapure and J. Kozinski, 2011. Supercritical fluid extraction and selective fractionation of polyunsaturated fatty acids from fungal biomass. Proceedings of the 242nd ACS National Meeting and Exposition, ACS National Meeting Book of Abstracts, Aug. 28-Sept. 1 Denver, $\mathrm{CO}$.

Doultani, S., K.N. Turhan and M.R. Etzel, 2003. Whey protein isolate and glycomacropeptide recovery from whey using ion exchange chromatography. J. Food Sci., 68: 1389-1395. DOI: 10.1111/j.13652621.2003.tb09655.x

Durling, N.E., O.J. Catchpole, J.B. Grey, R.F. Webby and K.A. Mitchell et al., 2007a. Extraction of phenolics and essential oil from dried sage (Salvia Officinalis) using ethanol-water mixtures. Food Chem., 101: 1434-1441. DOI: 10.1016/j.foodchem.2006.03.050

Durling, N.E., O.J. Catchpole, S.J. Tallon and J.B. Grey, 2007b. Measurement and modelling of the solubility of the ternary phase equilibria for high pressure carbon dioxide-ethanol-water mixtures. Fluid Phase Equilibria, 252: 103-113. DOI: 10.1016/j.fluid.2006.12.014

Eltringham, W. and O.J. Catchpole, 2008. Processing of Fish Oils by Supercritical Fluids. In: Supercritical Fluid Extraction of Nutraceuticals and Bioactive Compounds, Martinez, J.L. (Ed.), CRC Press, Taylor and Francis Group, Boca Raton, ISBN-13: 9780849370892.

EPA, 1994. Chemical summary for n-butanol. Office of Health and Environmental Assessment, Cincinnati. United States Environmental Protection Agency.

Fages, J., H. Lochard, J.J. Letourneau, M. Sauceau and E. Rodier, 2004. Particle generation for pharmaceutical applications using supercritical fluid technology. Powder Technol., 141: 219-219. DOI: 10.1016/j.powtec.2004.02.007

Fletcher, K., A.J. Fletcher, O.J. Catchpole and J.B. Grey, 2003. Extraction of compounds from dairy products. US7919131, WO2004066744 A1.

Fonterra, 2012. Dairy complex lipids.

Garcia, V., J. Pakkila, H. Ojamo, E. Muurinen and R.L. Keiski, 2011. Challenges in biobutanol production: How to improve the efficiency? Renew. Sustain. Energy Rev., 15: 964-980. DOI: 10.1016/j.rser.2010.11.008

Ginty, P.J., M.J. Whitaker, K.M. Shakesheff and S.M. Howdle, 2005. Drug delivery goes supercritical. Mater. Today. DOI: 10.1016/S13697021(05)71036-1 
Gupta, R.B. and J.J. Shim, 2006. Solubility in Supercritical Carbon Dioxide. 1st Edn., CRC Press, Boca Raton, ISBN-13: 9780849342400, pp: 960.

Haraldsson, G.G., B. Kristinsson, R. Sigurdardottir, G.G. Gudmundsson and H. Breivik, 1997. The preparation of concentrates of eicosapentaenoic acid and docosahexaenoic acid by lipase-catalyzed transesterification of fish oil with ethanol. J. Am. Oil Chem. Soc., 74: 1419-1424. DOI: 10.1007/s11746997-0247-1

Higashidate, S., Y. Yamauchi and M. Saito, 1990. Enrichment of eicosapentaenoic acid and docosahexaenoic acid esters from esterified fish oil by programmed extraction-elution with supercritical carbon dioxide. J. Chromatography, A515: 295-303. DOI: 10.1016/S0021-9673(01)89324-9

Jessop, P.G. and B. Subramaniam, 2007. Gas-expanded liquids. Chem. Rev., 107: 2666-2694. DOI: 10.1021/cr040199o

Jin, C., M. Yao, H. Liu, F. Fon and C. Lee et al., 2011. Progress in the production and application of nbutanol as a biofuel. Renew. Sustain. Energy Rev., 15: 4080-4106. DOI: 10.1016/j.rser.2011.06.001

Jung, J. and M. Perrut, 2001. Particle design using supercritical fluids: Literature and patent survey. J. Supercritical Fluids, 20: 179-179. DOI: 10.1016/S0896-8446(01)00064-X

KD-Pharma, 2012. Patented super critical fluid technology.

King, M.B. and T.R. Bott, 1992. Extraction of Natural Products using Near-Critical Solvents. 1st Edn., Springer, London, ISBN-10: 0751400696, pp: 336.

Knez, Z., 2009. Enzymatic reactions in dense gases. J. Supercritical Fluids, 47: 357-372. DOI: 10.1016/j.supflu.2008.11.012

Krichnavaruk, S., A. Shotipruk, M. Goto and P. Pavasant, 2008. Supercritical carbon dioxide extraction of astaxanthin from Haematococcus pluvialis with vegetable oils as co-solvents. Bioresource Technol., 99: 5556-5560. DOI: 10.1016/j.biortech.2007.10.049

Kumar, M. and K. Gayen, 2011. Developments in biobutanol production: New insights. Applied Energy, 88: 1999-2012. DOI: 10.1016/j.apenergy.2010.12.055

Lack, E. and H. Seidlitz, 1992. Commercial Scale Decaffeination of Coffee and Tea using Supercritical $\mathrm{CO}_{2}$. In: Extraction of Natural Products using Near-Critical Solvents, King, M.B. and T.R. Bott, (Eds.)., Blackie Academic and Professional, Glasgow, London, ISBN-10: 0751400696, pp: 100-139.
Laitinen, A. and J. Kaunisto, 1999. Supercritical fluid extraction of 1-butanol from aqueous solutions. J. Supercritical Fluids, 15: 245-252. DOI: 10.1016/S0896-8446(99)00011-X

Lawson, L.D. and B.G. Hughes, 1988. Triacylglycerol structure of plant and fungal oils containing $\gamma$ linolenic acid. Lipids, 23: 313-317. DOI: 10.1007/BF02537340

Lim, G., S. Lee, E. Lee, S. Haam and W. Kim, 2002. Separation of astaxanthin from red yeast Phaffia rhodozyma by supercritical carbon dioxide extraction. Biochem. Eng. J., 11: 181-187. DOI: 10.1016/S1369-703X(02)00023-2

Linder, M., E. Matouba, J. Fanni and M. Parmentier, 2002. Enrichment of salmon oil with n-3 PUFA by lipolysis, filtration and enzymatic re-esterification. Eur. J. Lipid Sci. Technol., 104: 455-462. DOI: 10.1002/1438-9312(200208)104:8

MacKenzie, A., M. Vyssotski and E. Nekrasov, 2009. Quantitative analysis of dairy phospholipids by ${ }^{31} \mathrm{P}$ NMR. J. Am. Oil Chem. Soc., 86: 757-763. DOI: 10.1007/s11746-009-1403-6

Martinez, J.L., 2008. Supercritical Fluid Extraction of Nutraceuticals and Bioactive Compounds. 1st Edn., CRC Press, Boca Raton, FL., ISBN-10:0849370892, pp: 402.

Mendes, R., 2008. Supercritical Extraction of Active Compounds from Algae. In: Supercritical Fluid Extraction of Nutraceuticals and Bioactive Compounds, Martinez, J.L. (Ed.), CRC Press, Boca Raton, FL., ISBN-10: 0849370892, pp: 189-204.

Montanes, F., O.J. Catchpole, S. Tallon, K. Mitchell and K. Lagutin, 2012. Semi-preparative supercritical chromatography scale plant for polyunsaturated fatty acids purification. J. Supercritical Fluids. DOI: 10.1016/j.supflu.2012.11.018

Mukhopadhyay, M., 2000. Natural Extracts Using Supercritical Carbon Dioxide. 4th Edn., CRC Press, Boca Raton, FL., ISBN-10: 0849308194, pp: 339.

Munio, M.M., L. Esteban, A. Robles, E. Hita and M.J. Jimenez et al., 2008. Synthesis of 2monoacylglycerols rich in polyunsaturated fatty acids by ethanolysis of fish oil catalyzed by 1,3 specific lipases. Process Biochem., 43: 1033-1039. DOI: $10.1016 /$ j.procbio.2008.05.006

Nilsson, W.B., E.J. Gauglitz Jr., J.K. Hudson, V.F. Stout and J. Spinelli, 1988. Fractionation of menhaden oil ethyl esters using supercritical fluid $\mathrm{CO}_{2}$. J. Am. Oil Chem. Soc., 65: 109-117. DOI: 10.1007/BF02542560 
Nisha, A., K.U. Sankar and G. Venkateswaran, 2012. Supercritical $\mathrm{CO}_{2}$ extraction of Mortierella alpina single cell oil: Comparison with organic solvent extraction. Food Chem., 133: 220-226. DOI: 10.1016/j.foodchem.2011.12.081

Olaizola, M., 2003. Commercial development of microalgal technology: From the test tube to the market place. Biomol. Eng., 20: 459-466. DOI: 10.1016/S1389-0344(03)00076-5

Oudshoorn, A., L.A.M.V.D. Wielen and A.J.J. Straathof, 2009. Assessment of options for selective 1-butanol recovery from aqueous solution. Ind. Eng. Chem. Res., 48: 7325-7336. DOI: 10.1021/ie900537w

Panagiotopoulos, A.Z. and R.C. Reid, 1986. Multiphase high pressure equilibria in ternary aqueous systems. Fluid Phase Equilibria, 29: 525-534. DOI: 10.1016/0378-3812(86)85051-8

Perrut, M., R.M. Nicoud and H. Breivik, 1998. Processes for chromatographic fractionation of fatty acids and their derivatives. US5719302.

Pettinello, G., A. Bertucco, P. Pallado and A. Stassi, 2000. Production of EPA enriched mixtures by supercritical fluid chromatography: From the laboratory scale to pilot plant. J. Supercritical Fluids, 19: 51-60. DOI: 10.1016/S08968446(00)00072-3

Pozo, M and W. Streett, 1984. Fluid phase equilibria for the system dimethylether/water from 50 to $220^{\circ} \mathrm{C}$ and pressures to $50.9 \mathrm{MPa}$. J. Chem. Eng. Data, 29: 324-329. DOI: $10.1021 / \mathrm{je} 00037 \mathrm{a} 030$

Quan, C., S. Li, S. Tian, H. Xu and A. Lin et al., 2004. Supercritical fluid extraction and clean-up of organochlorine pesticides in ginseng. J. Supercritical Fluids, 31: 149-157. DOI: 10.1016/j.supflu.2003.11.003

Ranjan, A. and V.S. Moholkar, 2012. Biobutanol: Science, engineering and economics. Int. J. Energy Res., 36: 277-323. DOI: 10.1002/er. 1948

Ratledge, C. and Z. Cohen, 2008. Microbial and algal oils: Do they have a future for biodiesel or as commodity oils? Lipid Technol., 20: 155-160. DOI: 10.1002/lite.200800044

Roh, M.K., M.S. Uddin and B.Y. Chun, 2008. Extraction of fucoxanthin and polyphenol from Undaria pinnatifida using supercritical carbon dioxide with co-solvent. Biotechnol. Bioprocess Eng., 13: 724729. DOI: $10.1007 / \mathrm{s} 12257-008-0104-6$

Rubio-Rodriguez, N., S. Beltran, I. Jaime, S.M.D. Diego and M.T. Sanz et al., 2010. Production of omega-3 polyunsaturated fatty acid concentrates: A review. Innov. Food Sci. Emerg. Technol., 11: 1-12. DOI: 10.1016/j.ifset.2009.10.006
Sakaki, K., T. Yokochi, O. Suzuki and T. Hakuta, 1990. Supercritical fluid extraction of fungal oil using $\mathrm{CO}_{2}, \mathrm{~N}_{2} \mathrm{O}, \mathrm{CHF}_{3}$ and $\mathrm{SF}_{6}$. J. Am. Oil Chem. Soc., 67: 553-557. DOI: 10.1007/BF02540765

Sako, T., T. Yokochi, M. Sato, O. Suzuki and T. Hakuta et al., 1989. Process for extracting lipids from Mortierella genus fungi. US4857329.

Schonemann, H., A. Gudinas, K. Williams, P. Wetmore and V. Krukonis, 2008. Method for extraction and concentration of carotenoids using supercritical fluids. US7329789.

Secuianu, C., V. Feroiu and D. Geana, 2004. Highpressure vapor-liquid equilibria in the system carbon dioxide +1 -butanol at temperatures from 293.15 to 324.15 K. J. Chem. Eng. Data, 49: 1635-1638. DOI: 10.1021/je0499521

Sho, A. and Y. Sugiyama, 2010. Novel functionality of glycolipids from brown seaweeds. Proceedings of the 101st AOCS Annual Meeting and Expo, (AME' 10), Phoenix, Arizona, USA.

Shoyele, S.A. and S. Cawthorne, 2008. Particle engineering techniques for inhaled biopharmaceuticals. Adv. Drug Delivery Rev., 58: 1009-1029. DOI: 10.1016/j.addr.2006.07.010

Snoey-Elich, H., 2001. Novel method for preparing eicosapentaenoic acid. ES2159257 A1, WO0136369.

Taki, S., E. Badens and G. Charbit, 2001. Controlled release system formed by supercritical anti-solvent coprecipitation of a herbicide and a biodegradable polymer. J. Supercritical Fluids, 21: 61-70. DOI: 10.1016/S0896-8446(01)00076-6

Tallon, S. and O.J. Catchpole, 2004. Measurement and modeling of the solubility of phosphatidylcholine in dimethylether and water. Proceedings of the AIChE Annual Meeting Conference, (AMC' 04), pp: 3427-3431.

Tallon, S., O. Catchpole, K. Fenton and A. Learmonth, 2005. Denaturation of egg yolk proteins during processing with near-critical dimethylether. Proceedings of the 2005 AIChE Annual Meeting, Cincinnati, Oct. 30-Nov. 4, AIChE.

Tallon, S.J. and O.J. Catchpole, 2008. Supercritical fluid processing of organic compounds. Chem. New Zealand, 72: 151-154.

Tandya, A., R. Mammucari, F. Dehghani and N.R. Foster, 2007. Dense gas processing of polymeric controlled release formulations. Int. J. Pharm., 328: 1-11. DOI: 10.1016/j.ijpharm.2006.08.016

Taylor, L.T., 2009. Supercritical fluid chromatography for the 21 st century. J. Supercritical Fluids, 47: 566573. DOI: $10.1016 /$ j.supflu.2008.09.012 
Taylor, M.K., T.M. Young, C.E. Butzke and S.E. Ebeler, 2000. Supercritical fluid extraction of 2,4,6trichloroanisole from cork stoppers. J. Agric. Food Chem., 48: 2208-2211. DOI: 10.1021/jf991045q

Vagi, E., O. Catchpole, W. Eltringham, A. MacKenzie and D. Scott, 2009. Lipase catalyzed alcoholysis of vegetable and fish oils coupled with selective separation with supercritical carbon dioxide extraction. Proceedings of the 9th International Symposium on Supercritical Fluids, (ISSF' 09), Arcachon, France.

Waibel, B.J., W.C. Morton and S.M. Cope, 2008. Dense gas means of extraction of a solute from solids. US7897050.

Weber, A., O. Catchpole and W. Eltringham, 2008. Supercritical fluid assisted, integrated process for the synthesis and separation of different lipid derivatives. J. Separation Sci., 31: 1346-1351. DOI: 10.1002/jssc.200800082

Wen, Z.Y. and F. Chen, 2005. Prospects for Eicosapentaenoic Acid Production using Microorganisms. In: Single Cell Oils, Cohen, Z.C. and C. Ratledge, (Eds.), AOCS Publishing, USA., ISBN-10: 1893997804.

Wijesinghe, W.A.J.P. and Y.J. Jeon, 2012. EnzymeAssistant Extraction (EAE) of bioactive components: A useful approach for recovery of industrially important metabolites from seaweeds: A review. Fitoterapia, 83: 6-12. DOI: 10.1016/j.fitote. 2011.10 .016
Winkler, S. and K. Stephan, 1997. Fluid multiphase behavior in ternary mixtures of $\mathrm{CO}_{2}, \mathrm{H}_{2} \mathrm{O}$ and 1butanol. Fluid Phase Equilibria, 137: 247-263. DOI: 10.1016/S0378-3812(97)00066-6

Wisniak, J. and E. Korin, 2005. Supercritical Fluid Extraction of Lipids and Other Materials from Algae. In: Single Cell Oils, Cohen, Z.C. and C. Ratledge, (Eds.), AOCS Publishing, USA., ISBN10: 1893997804.

Wynn, J. and C. Ratledge, 2007. Microbial Oils: Production, Processing and Markets for Specialty Long-Chain Omega-3 Polyunsaturated Fatty Acids. In: Long-Chain Omega-3 Specialty Oils, Brevik, H. (Ed.), Oily Press, Bridgwater, England, ISBN-10: 0955251214, pp: 43-76.

Yano, N., I. Fukinbara, M. Takano, 1978. Extracting foods with a dimethylether-water mixture. US4069351.

Yuan, J., A. Ai, Z. Zhang, R. Yan and Q. Zeng et al., 2011. Microbial oil production by Trichosporon cutaneum B3 using cassava starch. Shengwu Gongcheng Xuebao/Chinese J. Biotechnol., 27: 453460. PMID: 21650027

Zydney, A.L., 1998. Protein separations using membrane filtration: New opportunities for whey fractionation. Int. Dairy J., 8: 243-250. DOI: 10.1016/S09586946(98)00045-4 